Aus der Poliklinik für Zahnärztliche Prothetik

(Prof. Dr. med. dent. R. Bürgers)

im Zentrum Zahn-, Mund- und Kieferheilkunde

der Medizinischen Fakultät der Universität Göttingen

\title{
Vergleichende lichtmikroskopische
}

Untersuchung von gesundem und erkranktem parodontalem Ligament (PDL)

des Menschen

\author{
INAUGRAL-DISSERTATION \\ zur Erlangung des Doktorgrades für \\ Zahnheilkunde \\ der Medizinischen Fakultät der Georg- \\ August-Universität zu Göttingen
}

vorgelegt von

Hauke Schories

aus

Mainz

Göttingen 2014 
Dekan: Prof. Dr. rer. nat. H. K. Kroemer

I. Berichterstatter/in: Prof. Dr. med. N. Miosge

II. Berichterstatter/in: Prof. Dr. med. dent. A. Wiegand

III. Berichterstatter/in: Prof. Dr. med. M. Oppermann

Tag der mündlichen Prüfung: 16. September 2014 


\section{INHALTSVERZEICHNIS}

1 EINLEITUNG

1.1 Anatomie und Physiologie des Zahnhalteapparates

1.2 Parodontitis

1.3 Stand der Literatur zur histologischen Untersuchung des Zahnhalteapparates

1.4 Aufgabenstellung

2 MATERIAL UND METHODEN

2.1 Patientenkollektiv und Probenentnahme

2.2 Präparation des Probenmaterials

2.3 Fixierung, Entkalkung und Einbettung

2.4 Anfertigung der histologischen Schnitte

2.5 Entparaffinierung und Rehydrierung

2.6 Immunhistochemische Färbung

2.7 Verwendete Antikörper

2.8 Gegenfärben, Rehydrieren, Decken

2.9 Hämatoxylin-Eosin (H.E.)-Färbung

2.10 Durchführung

3 ERGEBNISSE

3.1 Allgemeine Qualität der Präparate

3.2 Der immunhistochemische Nachweis von Entzündungsmarkern im klinisch gesunden und erkranktem PDL 
3.3 Histologische Charakterisierung von Fibroblasten und zementnahen Zellen im klinisch gesunden und erkranktem PDL

3.4 Der immunhistochemische Nachweis von Kollagenen der EZM im klinisch gesunden und erkranktem PDL

3.5 Der immunhistochemische Nachweis von ausgesuchten

Stammzellmarkern/Adhäsionsmolekühlen im klinisch gesunden und erkranktem PDL

4 DISKUSSION

4.1 Diskussion der verwendeten Entzündungsmarker

4.2 Diskussion der histologischen Charakterisierung von Fibroblasten und zementnahen Zellen

4.3 Diskussion des Nachweises von Kollagen I, III, IV und XII

4.4 Diskussion der Stammzellmarker/Adhäsionsmoleküle CD 29, CD 44 und CD 90

5 ZUSAMMENFASSUNG

6 ANHANG

6.1 Abbildungsverzeichnis

6.2 Tabellenverzeichnis

6.3 Abkürzungsverzeichnis 


\section{EINLEITUNG}

\subsection{Anatomie und Physiologie des Zahnhalteapparates}

Der Zahnhalteapparat - auch Parodont genannt - setzt sich aus vier verschiedenen Geweben zusammen. Der Alveolarknochen und das Wurzelzement stellen die Hartgewebskomponenten dar, während die beiden Weichgewebsanteile durch die Gingiva und das parodontale Ligament (PDL) vertreten werden (Bartold et al. 2000, Bartold und Narayanan 2006) (siehe Abbildung 1A und B). Jedes dieser Gewebe hat eine spezialisierte Struktur, die in direktem Zusammenhang mit ihrer Funktion steht (Nanci und Bosshardt 2006). Zu den Hauptaufgaben des Parodontiums zählt neben der Verankerung des Zahns im Knochen (Hassel 1993, Nanci und Bosshardt 2006) auch die Abwehrfunktion (Schroeder und Listgarten 1997).

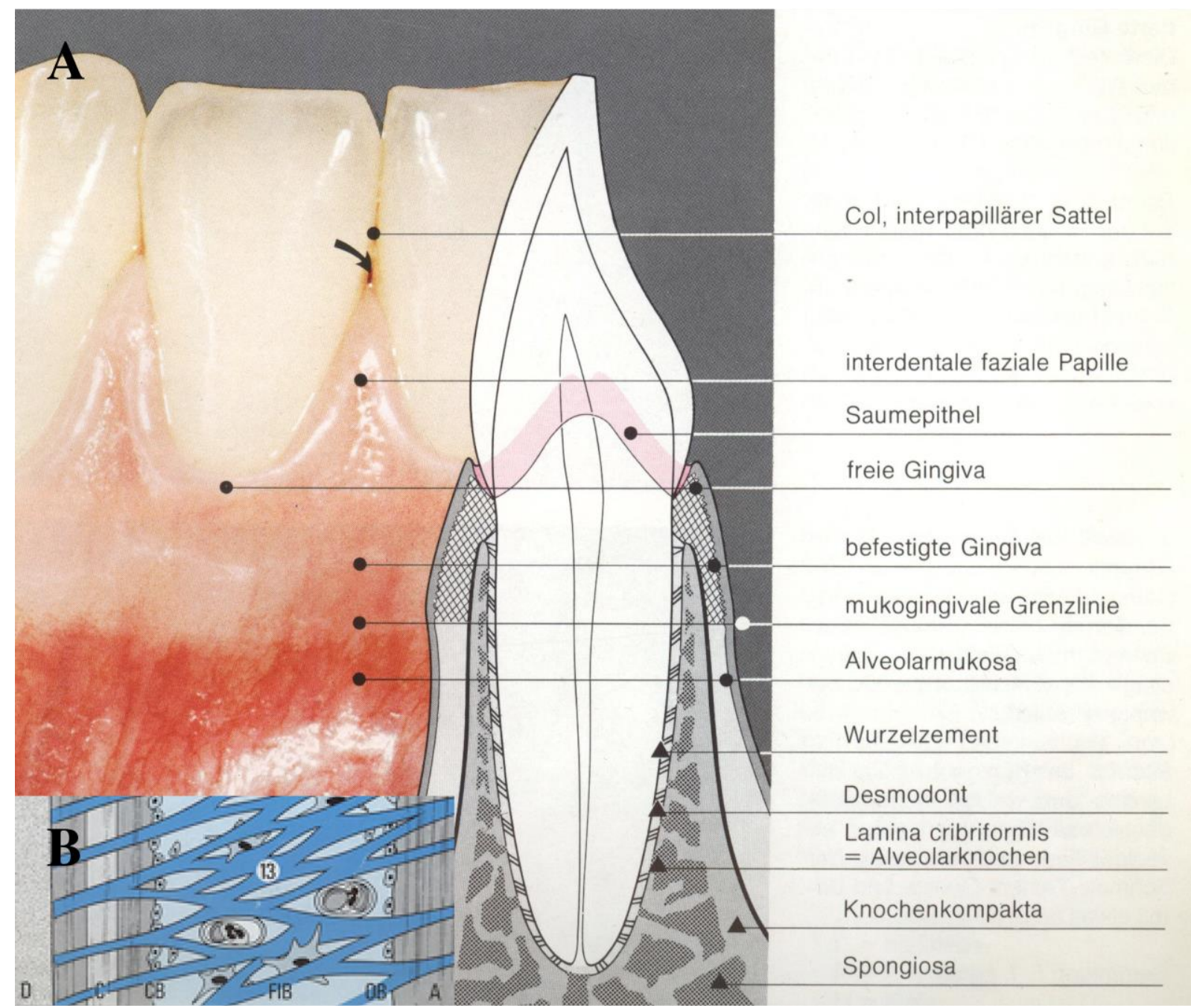

Abbildung 1: Aufbau des Zahnhalteapparates. A: Parodontale Strukturen; aus: Rateitschak et al 1989, Seite 1; B: schematische Detailansicht des PDL; aus: Rateitschak et al. 1989, Seite 7; „D“ = Dentin; „C“ = Wurzelzement; „,CB“ = zementnahe Zellen; „FIB“ = Fibroblasten; „,OB“ = Osteoblasten; „A“ = Alveolarknochen; 


\subsubsection{Die Gingiva}

Die Gingiva stellt den äußersten Bestandteil des Zahnhalteapparates dar und bedeckt somit im gesunden Zustand alle weiteren Bestandteile des Parodonts (Bartold et al. 2000). Topographisch lässt sie sich in eine freie und eine befestigte (attached) Gingiva unterteilen (Orban 1948). Die freie Gingiva reicht bis zur gingivalen Furche, die mikroskopisch einer Kerbe im Epithel entspricht, wo sie in die befestigte Gingiva übergeht. Diese Furche ist jedoch nur bei ungefähr einem Drittel aller Menschen aufzufinden (Ainamo und Löe 1966). Die Höhe der freien Gingiva nimmt mit fortschreitendem Alter zu (Ainamo und Löe 1966). Bei der zahnärztlichen parodontalen Sondierung im Gesunden wird das sogenannte Saumepithel der freien Gingiva durchstoßen. Der Ansatz des Saumepithels befindet sich an der SchmelzZement-Grenze (Listgarten 1980). Somit erscheint die freie Gingiva im Gegensatz zur befestigten als beweglich. Auf der befestigten Gingiva sind makroskopisch eine Vielzahl charakteristischer kleiner Eindellungen erkennbar, die in ihrer Gesamtheit als Oberflächenstippelung bezeichnet werden (Bergström 1984). Die Stippel entstehen durch den Zug von Bindegewebsfasern, die von der Knochenhaut und dem Wurzelzement in das Epithel inserieren und sind ursächlich für die charakteristische Unverschieblichkeit (Karring und Löe 1970). Gaumenwärts (palatinal) fehlt die befestigte Gingiva. In Richtung der Wurzelspitze (apikal) geht die befestigte Gingiva an der sogenannten mukogingivalen Grenzlinie in die bewegliche Alveolarschleimhaut über, die sich aufgrund eines hohen Glykogengehalts im Epithel mit Schillerscher Jodlösung anfärben lässt (Schroeder und Theilade 1966).

Histologisch setzt sich die Gingiva aus drei verschiedenen Epithelien zusammen, die jeweils mit dem drunterliegendem gingivalen Bindegewebe (Lamina propria) verzapft sind (Karring und Löe 1970, Yura et al. 2000). Das orale Epithel stellt den größten Teil der Gingiva dar und ist der Mundhöhle zugewandt. Es hat den typischen Aufbau eines geringfügig verhornten Plattenepithels und setzt sich von zentral nach peripher aus den Schichten Stratum basale, spinosum, granulosum und corneum zusammen (Schroeder und Theilade 1966). Das dem Zahn zugewandte orale Sulkusepithel ähnelt dem oralen Epithel sehr, ist jedoch durch eine geringere Verhornung (Keratinisierung) gekennzeichnet (Schroeder und Listgarten 1971). Das Saumepithel grenzt in Richtung der Zahnkrone (koronal) an das orale Sulkusepithel und bildet hier den Boden des gingivalen Sulkus. Apikal endet es im Bereich der Schmelz-ZementGrenze und wird dort durch mitotisch aktive Basalzellen unterhalten (Schroeder und Listgarten 1997). Das Saumepithel bildet einen Kragen um die Zahnhalsregion, ist daher von 
außen nicht sichtbar und übernimmt eine zentrale Rolle in der Abwehrleistung des Parodonts (Bosshardt und Lang 2005). Hierbei proliferiert es in Richtung des Sulkus und weist unabhängig vom parodontalen Entzündungszustand eine konstant hohe Umsatzrate bei Primaten auf (Demetriou und Ramfjord 1972, Skougaard 1965, Skougaard 1970). Der dem Saumepithel angrenzende Bereich des gingivalen Bindegewebes ist durch einen ausgedehnten Gefäßplexus gekennzeichnet (Schroeder und Listgarten 1997). Überdies sind dort Abwehrzellen ständig vorhanden (Juhl et al. 1988, Schroeder 1973). Die größte Zellfraktion der Lamina propria stellen jedoch Fibroblasten dar, die überwiegend Kollagen vom Typ I und III synthetisieren (Narajanan und Page 1976).

\subsubsection{Der Alveolarknochen}

Der Alveolarknochen stellt einen spezialisierten Knochenanteil der Mundhöle dar und dient in erster Linie der Verankerung von Zahnwurzeln über Sharpey-Fasern in von ihm gebildeten Zahnfächern (Alveolen) (Schroeder 1986, Sodek und McKee 2000). Anatomisch besteht er aus einer der Mundhöle zugewandten äußeren Schicht kompakten Knochens (Substantia compacta), welche in eine die Alveole auskleidende Schicht Bündelknochens (bundle bone) übergeht. Zentral ist der Alveolarknochen schwammartig (Substantia spongiosa) aufgebaut (Hassel 1993, Nanci und Bosshardt 2006). Die Besonderheit des Bündelknochens besteht darin, dass er siebartig von vielen gefäßreichen Volkmann-Kanälen durchzogen ist und in diesen die Sharpey-Fasern inserieren (Hassel 1993, Nanci und Bosshardt 2006). Im gesunden Parodont folgt der Verlauf des Alveolarfortsatzes der Schmelz-Zement-Grenze in einem Abstand von ungefähr zwei bis drei Millimetern (Hassel 1993).

Das Bestehen des Alveolarfortsatzes ist zudem eng mit der vorhandenen Bezahnung (Dentition) verknüpft. Er entwickelt sich insbesondere im Zuge des Wurzelwachstums der Zahnfollikel und ist mit der Ausbildung des Wurzelzements und Desmodonts assoziiert (Ten Cate et al. 1971, Ten Cate und Mills 1972, Schroeder 1986). Ferner ist der Alveolarfortsatz ständigen Umbauprozessen unterworfen, die nicht nur auf den Zahndurchbruch beschränkt sind. Nach dem Verlust bleibender Zähne kommt es jedoch durch Inaktivitätsatrophie zur Rückbildung des Alveolarfortsatzes (Saffar et al. 1997). 


\subsubsection{Das PDL (Desmodont)}

Das PDL ist ein derbes Bindegewebe, das zwischen dem Wurzelzement eines Zahnes und seinem umgebenden Alveolarknochen liegt und ihn gelenkartig befestigt (Schroeder 2000). Seine Breite variiert zwischen 0,15 und 0,38 mm und nimmt mit zunehmendem Alter ab (Nanci und Bosshardt 2006). Ausgereiftes PDL-Gewebe kann in drei verschiedene Regionen unterteilt werden. Es setzt sich aus einem zell- und gefäßreichen knochennahen Anteil, einer mittleren Zone mit geringer Zellzahl und dünneren Kollagenfibrillen sowie einem zementnahen Abschnitt mit dichten, sorgfältig geordneten Kollagenbündeln zusammen (Carter und Sloan 1994).

Das PDL - auch Desmodont genannt - besteht überwiegend aus den primären kollagenen Faserbündeln (Hassel 1993), die auch als Sharpey-Fasern bezeichnet werden. Diese erscheinen im unbelasteten Zustand wellenförmig (Hassel 1993), sind zueinander parallel ausgerichtet und verlaufen geradlinig (Raspanti et al. 2000). Überdies erscheinen sie in einem Winkel von ungefähr $30^{\circ}$ in Richtung der Wurzelspitze abgewinkelt (Raspanti et al. 2000) und sind im Zement sowie im Alveolarknochen verankert (Zwarych und Quigley 1965). Der geringere Anteil wird von lockerem Bindegewebe ausgefüllt, welches sekundäre Fasern, Gefäße, Nerven und verschiedene Zellpopulationen enthält. Die Funktion der sekundären Fasern, welche ungerichtet und zufällig orientiert erscheinen, ist bislang nicht ausreichend geklärt (Hassel 1993). Hervorzuheben sind jedoch die erstmals von Fullmer und Lillie (1958) wegen ihrer Säureresistenz als Oxytalan bezeichneten Fasern. Diese verlaufen als dreidimensionales Geflecht entlang der Zementoberfläche, umrunden hierbei die Wurzel und enden in einem apikalen Gefäßkomplex (Nanci und Bosshardt 2006). Ferner werden sie mit Nerven in Verbindung gebracht und es wird vermutet, dass sie durch ihre elastischen Eigenschaften funktionell mit der Registrierung und Regulierung des Blutflusses bei Auslenkungen der Zähne assoziiert sind (Nanci und Bosshardt 2006, Jonas und Riede 1980, Sims 1975).

Die Blutversorgung des PDL wird als reichlich beschrieben (Berkovitz 1990, Hassel 1993) und erfolgt durch oberhalb der Knochenhaut liegende Gefäße der Gingiva, den Zahn versorgende Gefäße und mit Hilfe von Gefäßen des Knochens, welche die Alveolenwände durchbrechen (Matsuo und Takahashi 2002). In funktioneller Hinsicht ermöglicht die reiche Blutversorgung eine initiale Abpufferung von Kaukräften durch eine Flüssigkeitsverschiebung in benachbarte Knochenmarksräume (Bien 1966). 


\subsubsection{Zellpopulationen des PDL}

Zellulär besteht das PDL überwiegend aus einer heterogenen Population von Fibroblasten (Bevelander und Nakahara 1968, Lekic et al. 1997, Roberts und Chamberlain 1978). Die Hauptaufgabe der Fibroblasten besteht in der Aufrechterhaltung der Gewebehomöostase. Sie sind im Allgemeinen mit der Proteinsynthese und Sekretion der EZM assoziiert (Nanci und Bosshardt 2006). Neben der Synthese von Kollagenfibrillen sind Fibroblasten auch an deren Resorption beteiligt (Cho und Garant 2000).

Laut Schroeder (2000) sind knochenbildende Osteoblasten und knochenabbauende Osteoklasten ständig im reifen PDL vorhanden. Anzutreffen sind sie in knochennahen Bereichen, in denen gerade ein molekularer Umbau (Remodeling) stattfindet. Dagegen sollen zementbildende Zementoblasten und zementabbauende Dentoklasten nur während Phasen des aktiven Zementanbaus im reifen PDL vorkommen. Zementoblasten werden als große in der Form variable Zellen mit einem charakteristisch basophilen Zytoplasma beschrieben (Bosshardt und Schroeder 1990). Fibroblastenähnliche Zellen, die eine erhöhte Aktivität alkalischer Phosphatase zeigen und in der Lage sind, an ein sogenanntes cementum attachment-Protein (CAP) zu binden, konnten insbesondere in unmittelbarer Nähe zum Zement und Alveolarknochen nachgewiesen werden (Groneveld et al. 1995, Groneveld et al. 1996, Liu et al. 1997). In vitro wurde gezeigt, dass diese mutmaßlich undifferenzierten Stammzellen vom osteoblastischen Typ nach entsprechender Stimulation dazu fähig sind, knochen- beziehungsweise zementähnliches mineralisiertes Gewebe zu synthetisieren (Liu et al. 1997).

Einen weiteren Zelltyp im Desmodont stellen die Epithelreste von Malassez dar. Diese sind als Überbleibsel der wurzelbildenden Hertwigschen Epithelscheide in zementnahen Regionen und Bereichen zwischen den Zahnwurzeln (Furkationen) als Zellnester eines epithelialen Netzwerkes anzutreffen (Becktor et al. 2007). Ihr Vorkommen nimmt mit zunehmendem Alter ab (Becktor et al. 2007, Wesselink und Beertsen 1993). 


\subsubsection{Das Wurzelzement}

Wurzelzement ist ein spezialisiertes hartes avaskuläres Gewebe, das dem Wurzeldentin aller Zähne von Säugetieren aufgelagert ist (Hassel 1993). Während der Zementogenese werden Sharpey-Fasern in das Wurzelzement eingelagert (Bosshardt und Selvig 1997). Über diese ist der Zahn wiederum - wie zuvor beschrieben - am Alveolarknochen befestigt.

Histologische Untersuchungen haben gezeigt, dass Wurzelzement in seinem Aufbau Knochen ähnelt (Hassel 1993, Selvig 1965), jedoch ist dessen Zellumsatz deutlich geringer (Roberts und Chase 1981). Seine anorganische Komponente macht ungefähr 46\% aus (Selvig 1965). Die organische Matrix des Wurzelzements besteht zu circa 90\% aus Kollagen Typ I und 5\% aus Kollagen Typ III (Birkedal-Hansen et al. 1977).

Das Wurzelzement ist nicht einheitlich aufgebaut und kann in die vier Haupttypen azelluläres, afibrilläres Zement, azelluläres Fremdfaserzement, zelluläres Eigenfaserzement und zelluläres Gemischtfaserzement eingeteilt werden (Schroeder 1986). Azelluläres, afibrilläres Zement ist vereinzelt dem Zahnschmelz aufgelagert und insbesondere im Bereich der Schmelz-ZementGrenze zu finden. Es ist frei von Zementozyten und kollagenen Fibrillen (Bosshardt und Selvig 1997) und seine funktionelle Bedeutung ist bislang unbekannt (Cho und Garant 2000). Das azelluläre Fremdfaserzement ist primär der koronalen Hälfte des Wurzeldentins aufgelagert (Hassel 1993). Das zervikale Drittel der Wurzeloberfläche wird ausschließlich von ihm bedeckt (Schroeder 2000). Als Bestandteil des zellulären Gemischtfaserzements entsteht es im apikalen Bereich erst sekundär (Bosshardt und Selvig 1997). Ferner beherbergt das azelluläre Fremdfaserzement eine große Anzahl inserierender Sharpey-Fasern und nimmt somit die funktionell bedeutendste Stellung aller Zementarten in der Zahnverankerung ein (Nanci und Bosshardt 2006). Gebildet wird es von miteinander verbundenen Zellen, die ein gut entwickeltes raues endoplasmatisches Retikulum (ER) aufweisen und Fibroblasten ähneln (Bosshardt und Selvig 1997). Zelluläres Eigenfaserzement wird von Zementoblasten primär im apikalen Bereich des Wurzeldentins sowie als Bestandteil des zellulären Gemischtfaserzements gebildet (Schroeder 2000). Diese Zellen sind groß, basophil und haben neben einem euchromatinreichen Kern auch ein gut ausgeprägtes ER (Bosshardt und Schroeder 1992, Bosshardt und Selvig 1997). Das zelluläre Eigenfaserzement weist keine SharpeyFasern auf (Hassel 1993) und kann eingemauerte Zementozyten beherbergen (Bosshardt und Schroeder 1990). Eine weitere wichtige Aufgabe des zellulären Eigenfaserzements ist seine reparative Funktion, wie zum Beispiel das Auffüllen von zuvor resorbierten Wurzelarealen 
Einleitung

(Bosshardt und Selvig 1997). Das zelluläre Gemischtfaserzement besteht aus alternierend aufeinander gelagerten Schichten azellulären Fremdfaserzements und zellulären Eigenfaserzements (Nanci und Bosshardt 2006). Es ist im apikalen Wurzeldrittel und bei mehrwurzligen Zähnen im Furkationsbereich angesiedelt und nimmt innerhalb der Zahnreihe in Richtung der Mahlzähne (Molaren) zu (Schroeder 2000). 


\subsection{Parodontitis}

\subsubsection{Bedeutung der Parodontitis}

In einer alternden Gesellschaft mit verbesserter Mundhygiene und ansteigender Lebenserwartung sind Parodontopathien immer mehr in den Fokus zahnärztlicher Behandlung gerückt. Die vierte deutsche Mundgesundheitsstudie konnte belegen, dass die Parodontitis Karies als Hauptursache für den Zahnverlust abgelöst hat. Über 70\% aller Erwachsenen leiden an einer Parodontitis, wobei mit zunehmenden Alter die Häufigkeit schwerer Verlaufsformen deutlich zunimmt (Deutsche Mundgesundheitsstudie 2006). Zudem konnte gezeigt werden, dass eine bestehende Parodontitis selber einen Risikofaktor für Volkskrankheiten wie zum Beispiel kardiovaskuläre Erkrankungen (Scannapieco et al. 2003) und Diabetes mellitus (Taylor 2001) darstellt.

\subsection{2 Ätiologie und Pathogenese}

Unter dem Begriff Parodontitis werden entzündliche Erkrankungen des Zahnhalteapparates unterschiedlicher Ätiologie subsumiert, bei denen es letztendlich zu einer irreversiblen Zerstörung von strukturellen Bestandteilen des Parodonts kommt (Listgarten 1986, Preshaw et al. 2004). Allen Formen bakteriell bedingter Parodontitiden liegt jedoch prinzipiell der gleiche pathologische Mechanismus zugrunde (Page et al. 1997). Einen Überblick über die Pathogenese liefert Abbildung 2.

Parodontopathogene Bakterien gelten als primärer ätiologischer Faktor für die Entstehung einer Entzündung des Parodonts (Page und Kornman 1997). Ähnlich wie die Karies stellt auch die Parodontitis eine biofilmassoziierte Erkrankung der Mundhöhle dar. Grundlage für ihre Etablierung stellt die Ablagerung von Glykoproteinen des Speichels auf der Zahnoberfläche dar, die als Pellikel bezeichnet wird (Hannig und Joiner 2006). An diese binden spezielle Pionierkeime und beginnen damit, ein Gerüst extrazellulärer Mehrfachzucker zu bilden, in das sie selber eingebettet sind (Duan et al. 1994, Kolenbrander und London 1993). Unter der Voraussetzung einer ungestörten Akkumulation kann es in Folge der Bakterienadhäsion zur Entwicklung eines strukturierten Biofilms - früher auch als Plaque bezeichnet - kommen (Whittaker et al. 1996). Die Organisation von Bakterien in Biofilmen bietet zahlreiche Vorteile wie zum Beispiel den Schutz vor Antibiotika (Reid 1999). Im Unterschied zur Karies ist für die Entstehung einer Parodontitis das Vordringen des Biofilms 
in Bereiche, die unterhalb des Zahnfleischsaums liegen (subgingival), entscheidend. Dieser Bereich ist dem Abrieb zum Beispiel durch Mundhygienemaßnahmen weniger zugänglich und dient als Quelle von Nährstoffen aus der Sulkusflüssigkeit (Darveau et al. 1997). Subgingivale Plaque lässt sich prinzipiell in 5 Komplexe verschiedener häufig gemeinsam vorkommender Bakterienpopulationen mit ähnlichen Eigenschaften einteilen. In Abhängigkeit der vorliegenden ökologischen Bedingungen - wie zum Beispiel einem sinkenden Sauerstoffgehalt - ermöglichen Bakterienpopulationen eines Komplexes die Etablierung von Bakterienarten eines anderen Komplexes (Socransky et al. 1998). Folglich sind nicht immer Bakterien aller Komplexe vorhanden. Mehrere Hundert verschiedene Bakterienarten konnten bereits in dem Zahn-anhaftenden Biofilmen identifiziert werden (Moore und Moore 1994). Eine herausragende Rolle nehmen jedoch wenige fakultativ oder strikt anaerobe pathogene Bakterien ein. Diese sind in tiefen Zahnfleischtaschen gehäuft anzutreffen und mit der Mehrzahl parodontaler Erkrankungen assoziiert (Consensus report 1996). Wichtige Vertreter stellen zum Beispiel Porphyromonas gingivalis, Tanerella forsythia, Treponema denticola und Aggregatibacter actinomycetemcomitans dar.

Obwohl die Anwesenheit einer parodontopathogenen Plaque notwendige Bedingung für die Entstehung einer bakteriellen Parodontitis ist, scheint diese allein jedoch nicht hinreichend zu sein. Die Ätiologie der Parodontitis muss also multifaktoriell bedingt sein (Page und Kornman 1997). Umweltfaktoren, erworbene und genetische Risikofaktoren sind ebenfalls für das Ausbrechen einer Parodontitis sowie für deren Progression von zentraler Bedeutung (Page et al. 1997). Diese werden auch als sekundäre Risikofaktoren bezeichnet. Die durch bakterielle Antigene ausgelöste Immunantwort des Wirts führt fast immer auch zu einer Zerstörung körpereigenen Gewebes (Page et al. 1997). Ursächlich hierfür sind Zytokine und Entzündungsmediatoren (Birkedal-Hansen 1993). Dennoch können sich bei normaler Wirtsabwehr destruktive und regenerative Prozesse in einer Art Gleichgewicht befinden (Page und Kornman 1997). Faktoren, die zu einer überschießenden Immunreaktion des Wirts führen, verschieben dieses Gleichgewicht jedoch in Richtung der Gewebezerstörung (Genco 1992). Es konnte gezeigt werden, dass Rauchen (Salvi et al. 1997) und Diabetes mellitus (Chávarry et al. 2009) mit einem höheren Verlust parodontaler Verankerung (Attachment) assoziiert sind. Dass auch genetische Faktoren Einfluss auf die Entwicklung einer Parodontitis haben, zeigte eine Studie mit Arbeitern in Sri Lanka, deren Zähne vergleichbar hohe Plaqueansammlungen aufwiesen. Alle Teilnehmer zeigten klinische Zeichen einer ent- 
zündeten Gingiva (Gingivitis), jedoch entwickelten 8\% einen schnell fortschreitenden, 81\% einen moderat fortschreitenden und 11\% nahezu keinen Attachmentverlust über einen Beobachtungszeitraum von 15 Jahren (Löe et al. 1986).

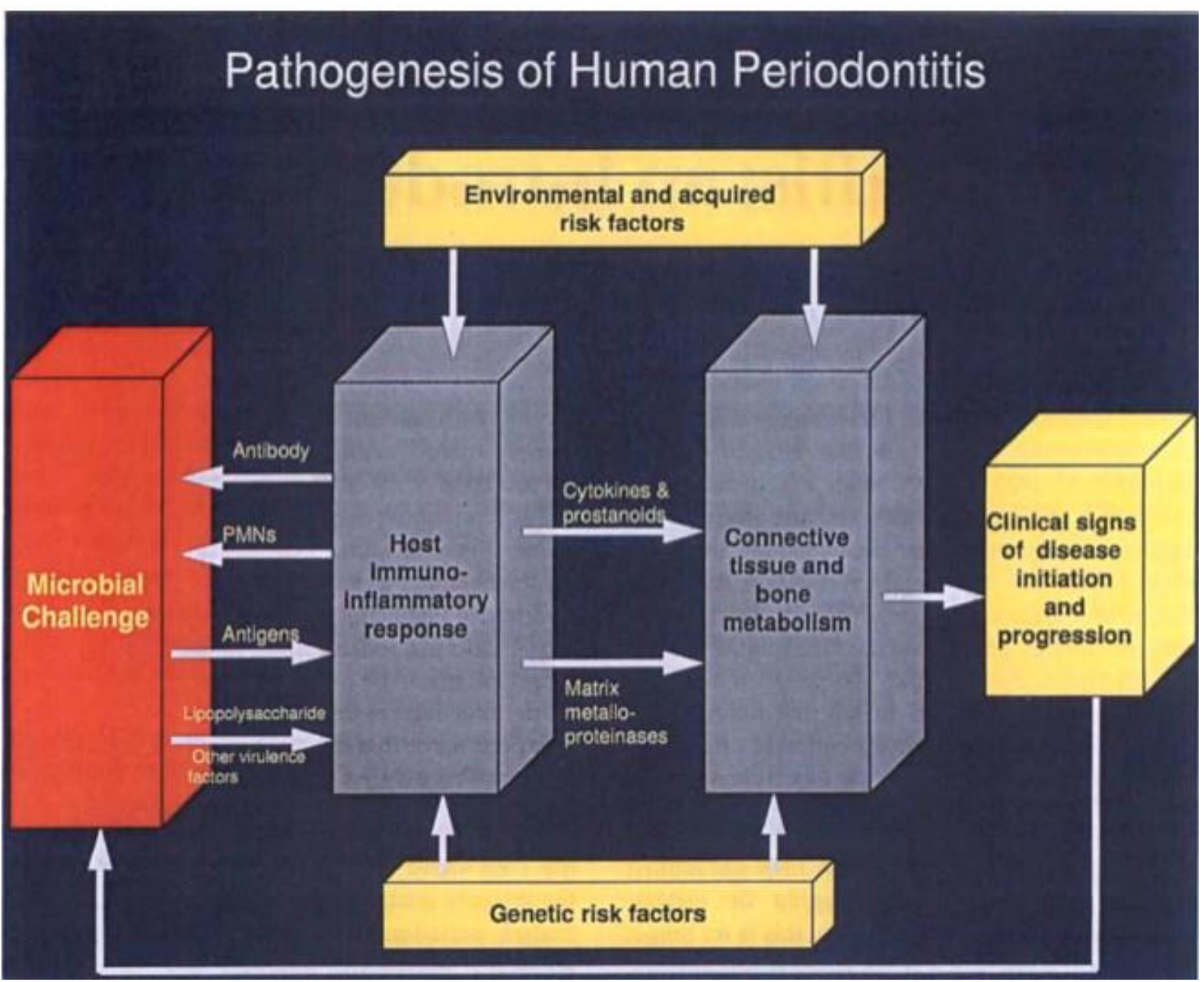

Abbildung 2: Pathogenese der Parodontitis. Aus: Page und Kornman 1997, Seite 10; 


\subsection{Stand der Literatur zur histologischen Untersuchung des Zahnhalteapparates}

Im Rahmen histologischer Untersuchungen war die Charakterisierung des Zahnhalteapparates bereits häufig Gegenstand wissenschaftlicher Forschung. Die meisten histologischen Experimente fanden jedoch insbesondere im Rahmen von Tierversuchen statt. Da der Zahnhalteapparat als funktionelle Einheit neben Gingiva, Zement und PDL auch aus Alveolarknochen besteht (Nanci und Bosshardt 2006), ist dessen wissenschaftliche Erforschung am Menschen aus ethischen Gründen erschwert. Folglich basiert ein Großteil der bereits gewonnen Evidenz auf tierexperimentellen Studien und ist zum Teil für den Menschen noch nicht nachgewiesen. Gleichwohl existieren einige wichtige charakterisierende histologische Studien über das gesunde menschliche PDL. In diesem Kontext stehen Studien zur Beschreibung der zellulären und strukturellen Bestandteile des PDL (z.B. Bevelander und Nakahara 1968, Raspanti et al. 2000) sowie von wichtigen Bestandteilen der EZM wie zum Beispiel Kollagenen (z.B. Becker et al. 1991, Lukinmaa und Waltimo 1992), Glykosaminoglykanen (z.B. Häkkinen et al. 1993, Leonardi et al. 2006) und Adhäsionsmolekülen (z.B. Lukinmaa et al. 1991, Zhang et al. 1993).

In jüngerer Vergangenheit wurde das menschliche PDL insbesondere hinsichtlich des Vorkommens von Stammzellen untersucht. In der Zellkultur wurden mit Hilfe von Markern für embryonales Bindegewebe Stammzellen im PDL identifiziert, welche die Fähigkeit besitzen, knochen-, knorpel- und fettähnliches Gewebe zu bilden (z.B. Trubiani et al. 2005, Gay et al. 2007, Nagatomo et al. 2006). Histologisch wurde bereits der Versuch unternommen, Stammzellnischen im PDL zu identifizieren. In Studien an Mäusen, unter Zuhilfenahme von radioaktiv markiertem Thymidin, konnte zum einen im experimentell verwundeten PDL gezeigt werden, dass sich der Großteil mitotisch aktiver Zellen in der Nähe von Blutgefäßen und zu circa 10\% zementnah befindet (Gould et al. 1977). Zum anderen wurden im intakten PDL thymidinmarkierte Zellen insbesondere in Knochenmarksräumen und mit diesen in Verbindung stehenden Bereichen beobachtet (McCulloch et al. 1987). Untersuchungen zur Identifizierung einer Stammzellnische im menschlichen PDL liegen kaum vor. Eine vergleichende histologische Untersuchung anhand von gesundem und erkranktem PDL wurde durch Chen et al. (2006) vorgenommen.

Zusammenfassend lässt sich festhalten, dass systematisch vergleichende histologische Untersuchungen des gesunden und pardontitisch erkrankten menschlichen PDL-Gewebes nach 
Einleitung

gegenwärtigem Kenntnisstand nicht vorhanden sind. Viele Fragestellungen, insbesondere in Bezug auf das PDL des Menschen, sind noch nicht ausreichend beantwortet. Diesbezüglich sind weitere Forschungsanstrengungen erforderlich. 


\subsection{Aufgabenstellung}

Die vorliegenden Arbeit soll dazu beitragen, den Wissensstand über das menschliche PDL zu erweitern. In diesem Rahmen soll die histologische Gegenüberstellung von gesundem und erkranktem PDL des Menschen im Mittelpunkt stehen, da wie bereits erwähnt ein Großteil der Forschung entweder durch Tierversuche oder nicht vergleichend erfolgte. Gegenstand der Untersuchung dieser Arbeit ist hierbei der abhängig vom parodontopathogenen Zustand weiter koronal liegende Abschnitt des PDLs ohne möglicherweise anhaftende Gingiva oder Granulationsgewebe. Im Zuge dessen soll zum einen der immunhistochemische Nachweis von Entzündungsmarkern erfolgen. Nach vorliegendem Kenntnisstand sind diesbezüglich keine vergleichenden histologischen Untersuchungen des menschlichen PDL vorgenommen worden. Ferner sollen Änderungen histologischer Charakteristika wie zum Beispiel der Fibroblasten und dem Zement anliegender Zellpopulationen unter dem Einfluss einer statthaften Parodontitis untersucht werden. In diesem Kontext steht auch der gegenüberstellende immunhistochemische Nachweis von Kollagenen, die einen wesentlichen Bestandteil des parodontalen Funktionsgewebes darstellen. Abschließend soll durch die vorliegende Arbeit weitere Evidenz über das Vorkommen und die Verteilung von Adhäsionsmolekülen, die auch als mutmaßliche mesenchymale Stammzellmarker bekannt sind, gewonnen werden. 


\section{MATERIAL UND METHODEN}

\subsection{Patientenkollektiv und Probenentnahme}

Die verwendeten Gewebeproben entstammen sechs Patienten (zwei Männern und vier Frauen) im Alter von 26 bis 71 Jahren, welchen nach rechtfertigender Indikation im Universitätsklinikum Göttingen Zähne gezogen wurden. Die Teilnehmer dieser Studie wurden über den Inhalt und Ablauf aufgeklärt. Ein entsprechender Ethikantrag (Nr. 27/2/09) wurde durch die Ethikkommission der Medizinischen Fakultät der Georg-August-Universität Göttingen genehmigt und lag zum Beginn der Studie vor. Parodontal erkrankte Zähne wiesen klinische Zeichen einer fortgeschrittenen Parodontitis marginalis auf, nämlich erhöhte Sondierungstiefen, einen fortgeschrittenen Attachmentverlust, einen positiven BOP und gegebenenfalls einen Furkationsbefall (bei mehrwurzeligen Zähnen). Zusätzlich war das röntgenologische Äquivalent fortgeschrittenen Knochenabbaus gegeben. Entsprechend wiesen parodontal gesunde Proben keine klinischen und röntgenologischen Zeichen einer Parodontitis marginalis auf und wurden zum Beispiel im Rahmen einer Weisheitszahnextraktion gewonnen. Überdies wurde bei jedem Patient eine umfassende Anamnese erhoben. Es wurden nur Patienten ausgewählt, die keine schweren Allgemeinerkrankungen aufwiesen. Gewonnene Proben wurden unverzüglich in 1 x PBS (pH 7,4) gelagert und innerhalb von 24 Stunden weiterverarbeitet.

\subsection{Präparation des Probenmaterials}

Die extrahierten Zähne wurden anschließend, unter Zuhilfenahme eines Technikhandstücks (K10 Handstück 4950 Kavo EWL, Biberach, Deutschland), mittels einer diamantierten Trennscheibe (918PB.104.220 Komet, Besigheim, Deutschland) unter ständiger Kühlung mit 1 x PBS (pH 7,4) in Richtung der Längsachse des Zahnes zerkleinert, um die Dauer der Entkalkung zu reduzieren. Es verblieben Wurzelfragmente, die Dentin, Zement und anheftendes Desmodont sowie gegebenenfalls Granulationsgewebe beinhalteten. Um den Einfluss möglicher periapikaler Entzündungsprozesse $\mathrm{zu}$ minimieren, wurde das untere Wurzeldrittel abgetrennt. Zudem wurde der Wurzel anheftendes Granulationsgewebe entfernt, da der Fokus dieser Arbeit auf das PDL-Gewebe gerichtet ist. 


\subsection{Fixierung, Entkalkung und Einbettung}

Anschließend erfolgte die Fixierung in gepuffertem Formalin 3,7\% nach Lillie. Hierzu wurde 1 Teil Formaldehyd 37\% (Merck, Darmstadt, Deutschland) mit 9 Teilen 0,1 M SörensenPuffer vermengt. Die Fixation erfolgte in sterilen $15 \mathrm{ml}$ fassenden Falcon-Tubes (Sarstedt, Nümbrecht, Deutschland) für mindestens 6, jedoch höchstens 24 Stunden in einem Kühlraum bei 4 bis $8^{\circ} \mathrm{C}$. Anschließend erfolgte die Entfernung der Fixans unter fließendem Leitungswasser für 15 Minuten.

Die nachfolgende Entkalkung erfolgte mit 20\%igem EDTA (pH 7,4), auf einem Wippschüttler (Elmi DRS-12, Riga, Lettland) in den bereits erwähnten Falcon Tubes. Der Ansatz erfolgte unter Verwendung von $895 \mathrm{ml}$ Aqua dest., das mit $105 \mathrm{ml} 5 \mathrm{~N} \mathrm{NaOH}$ und 200 g EDTA (Art. 8040.1 Roth, Karlsruhe Deutschland) versetzt wurde auf einem Magnetrührer bei $70{ }^{\circ} \mathrm{C}$ unter Kontrolle des pH-Werts. Während des ersten Monats erfolgte ein täglicher Austausch des EDTAs; anschließend alle 2 Tage. Die Präparate wurden so lange entkalkt, bis die sogenannte Nadelprobe positiv war. Vor der Einbettung wurden die Proben über Nacht in $70 \%$ igem Alkohol gelagert.

Diese erfolgte mit Hilfe eines Einbettautomaten (Shandon Duplex Processor, Runcorn, England) nach dem in Tabelle 1 aufgeführten Protokoll. Die Präparate wurden anschließend in speziellen Metallförmchen ausgerichtet, mit erwärmtem flüssigem Paraffin aufgefüllt und für circa 5 Minuten über einer Kühlplatte in einen festeren Zustand überführt. Die weitere Auskühlung erfolgte bei Raumtemperatur. 
Tabelle 1: Protokoll der Gewebedehydrierung und Überführung in Paraffin

\begin{tabular}{ccc}
\hline Abfolgeposition & Küvetteninhalt & Dauer der Behandlung \\
\hline eins & Ethanol $(70 \%)$ & 3 Stunden \\
zwei & Ethanol $(80 \%)$ & 1 Stunde \\
drei & Ethanol $(90 \%)$ & 1 Stunde \\
vier & Ethanol $(96 \%)$ & 1 Stunde \\
fünf & Ethanol $(100 \%)$ & 2 Stunden \\
sechs & Isopropylalkohol & 2 Stunden \\
sieben & Isopropylalkohol & 1,5 Stunden \\
acht & Xylol & 30 Minuten \\
neun & Xylol & 45 Minuten \\
zehn & Xylol & 45 Minuten \\
elf & Paraplast $\left(52^{\circ} \mathrm{C}\right)$ & 6 Stunden \\
zwölf & Paraplast $\left(56^{\circ} \mathrm{C}\right)$ & 4,5 Stunden \\
\hline
\end{tabular}

\subsection{Anfertigung der histologischen Schnitte}

Unter Zuhilfenahme eines Mikrotoms (Jung Biocut 2035 Leica, Nussloch, Deutschland) wurden circa $10 \mu \mathrm{m}$ dünne Paraffinschnitte angefertigt. Diese wurden anschließend in einem Wasserbad (Typ 1052 GFL, Burgwedel, Deutschland) platziert, über Objektträger (Superfrost ${ }^{\circledR}$ Plus Menzel, Braunschweig, Deutschland) aufgenommen und zunächst auf einer Wärmeplatte (Typ 14801 Medax, Rendsburg, Deutschland) bei $37^{\circ} \mathrm{C}$ vorgetrocknet. Schlussendlich wurden die Präparate für 24 Stunden in einen Wärmeschrank (Typ B 5042 Heraeus, Hanau, Deutschland) bei $37^{\circ} \mathrm{C}$ verbracht. 


\subsection{Entparaffinierung und Rehydrierung}

Die nun auf den Objektträgern positionierten Präparate wurden anschließend unter Zuhilfenahme eines Färbeautomaten (Stainix Diapath, Martinengo, Italien) entparaffiniert und rehydriert um einer nachfolgend stattfindenden immunhistochemischen Färbung zugänglich gemacht zu werden. Tabelle 2 listet das verwendete Protokoll auf.

Tabelle 2: Protokoll der Gewebeentparaffinierung und Rehydrierung

\begin{tabular}{ccc}
\hline Abfolgeposition & Küvetteninhalt & Dauer der Behandlung \\
\hline eins & Xylol & 5 Minuten \\
zwei & Xylol & 5 Minuten \\
drei & Ethanol $(100 \%)$ & 5 Minuten \\
vier & Ethanol $(90 \%)$ & 5 Minuten \\
fünf & Ethanol $(80 \%)$ & 5 Minuten \\
sechs & Ethanol $(60 \%)$ & 5 Minuten \\
sieben & Ethanol $(50 \%)$ & 5 Minuten \\
acht & 1 x PBS $(\mathrm{pH} 7,4)$ & 10 Minuten
\end{tabular}

\subsection{Immunhistochemische Färbung}

Für die immunhistochemische Färbung wurden die rehydrierten Proben mit verschiedenen primären Antikörpern behandelt. In Vorversuchen wurde zunächst ein gewebespezifisches Standardprotokoll (siehe Tabelle 3) etabliert. Verwendet wurde ein Detektionssystem das auf der indirekten LSAB-Methode beruht (Dako REALTM Detection Sytem Alkaline Phosphatase/ RED Rabbit/Mouse). Hierbei finden ungekoppelte Primärantikörper Verwendung, die aus Kaninchen oder Mäusen gewonnen werden müssen. Der konjugierte sekundäre Antikörper besteht aus biotinylierten Ziege-Anti-Maus und Ziege-Anti-Kaninchen Immunoglobinen und bindet an den Primärantikörper. An alkalische Phosphatase gekoppeltes Streptavidin bindet aufgrund seiner hohen Affinität an das Biotin des sekundären Antikörpers. Durch Zugabe eines Chromogens kommt es schließlich zur Bildung von unlöslichen Farbstoffen, also einer sichtbaren Färbungsreaktion. 
Tabelle 3: Protokoll für die Verwendung des Dako REALTM Detection Sytem Alkaline Phosphatase/RED Rabbit/Mouse

\begin{tabular}{|c|c|c|}
\hline Reihenfolge & Arbeitsanweisung & Dauer \\
\hline eins & Präparate mit Dako REAL ${ }^{\mathrm{TM}}$ Levamisole-Lösung benetzen & 10 Minuten \\
\hline zwei & Präparate in $1 \times$ PBS $(\mathrm{pH} 7,4)$ waschen & 10 Minuten \\
\hline drei & $\begin{array}{l}\text { Präparate mit Pro Taqs } 1 \text { bei } 60^{\circ} \mathrm{C} \text { im Wärmeschrank inkubieren (Biocyc, } \\
\text { Luckenwalde, Deutschland) }\end{array}$ & 20 Minuten \\
\hline vier & $\begin{array}{c}\text { Präparate in } 1 \text { x PBS (pH 7,4) waschen (P4417-100TAB Sigma-Aldrich, } \\
\text { St. Louis, USA) }\end{array}$ & 10 Minuten \\
\hline fünf & Vorverdau mit Protease 24 (P8038 Sigma-Aldrich, St. Louis, USA) & 2 Minuten \\
\hline sechs & Präparate in $1 \times$ PBS $(\mathrm{pH} 7,4)$ waschen & 10 Minuten \\
\hline sieben & $\begin{array}{l}\text { Präparate mit 1\%iger PBS/BSA-Lösung blocken (BSA: A9418-5G Sigma- } \\
\text { Aldrich, St.Louis, USA) }\end{array}$ & 10 Minuten \\
\hline acht & Inkubation mit ungekoppeltem primären Antikörper & je nach AK \\
\hline neun & Präparate in $1 \times$ PBS $(\mathrm{pH} 7,4)$ waschen & 10 Minuten \\
\hline zehn & Inkubation mit Dako REAL TM Biotinylated Secondary Antibodies (AB2) & 15 Minuten \\
\hline elf & Präparate in $1 \times$ PBS $(\mathrm{pH} 7,4)$ waschen & 10 Minuten \\
\hline zwölf & Inkubation mit Dako REAL ${ }^{\mathrm{TM}}$ Streptavidin Alkaline Phosphatase (AP) & 15 Minuten \\
\hline dreizehn & Präparate in 1 x PBS $(\mathrm{pH} 7,4)$ waschen & 10 Minuten \\
\hline vierzehn & Färben mit Dako REAL ${ }^{\mathrm{TM}}$ Chromogen Red-Lösung & unter Sicht \\
\hline fünfzehn & Präparate in $1 \times$ PBS $(\mathrm{pH} 7,4)$ waschen & 10 Minuten \\
\hline
\end{tabular}

\subsection{Verwendete Antikörper}

Die Antikörper Macrophage (HAM-56) und Kollagen Typ IV (CIV 22) sind monoklonale Mausantikörper. HAM-56 wurde speziell für eine immunzytochemische Studie menschlicher atherosklerotischer Läsionen entwickelt und reagiert mit Makrophagen und deren Vorläuferzellen (Monozyten), färbt jedoch auch eine Subpopulation kleiner Gefäße an (Gown et al. 1986). Der CIV 22-Antikörper fand bereits in mehreren immunhistochemischen Arbeiten Verwendung und diente zum Beispiel zur Identifikation der Basalmembran epithelialer Tumoren (Määttä et al. 2001). Der Antikörper CD 11b ist monoklonal, wurde aus Kaninchen gewonnen, ist gegen den entsprechenden menschlichen Carboxyl-Terminus gerichtet und wurde bereits zur Identifizierung von aktivierten PMN im Blut von Frauen mit Schwangerschaftshypertonie verwendet (Barden et al. 1997). Zudem konnte im Rahmen der vorliegenden Arbeit ein polyklonaler Anti-Neutrophil-Elastase-Antikörper, der mit dem menschlichen Elastase-Protein auf Leukozyten reagiert, genutzt werden. Im Zuge einer Publikation diente dieser zum lichtmikroskopischen Nachweis neutrophiler Infiltration der 
Augenhornhaut (Oh et al. 2010). Des weiteren wurden zwei polyklonale Antikörper genutzt, die aus dem Kaninchen stammen, wobei der eine gegen die alpha 1- und alpha 2-Kette von menschlichem Kollagen Typ I und der andere gegen die alpha 1-Kette von Kollagen Typ III gerichtet ist. Der durch Immunaffinitätschromatographie aufbereitete Kollagen Typ IAntikörper, zeigt nach Herstellerangaben eine Kreuzreaktivität mit anderen Kollagenen von unter einem Prozent und wurde bereits in mehreren Studien genutzt (z.B. Stefanovic et al. 2002). Ferner wurde ein aus Kaninchen gewonnener gegen Mensch und Maus gerichteter polyklonaler Kollagen Typ XII-Antikörper, der freundlicherweise von Professor Robert Burgeson überlassen wurde, verwendet (Lunstrum et al. 1992). Überdies konnte ein monoklonaler an das Carboxylende des menschlichen und murinen Integrins beta 1 (CD 29) bindender Antikörper zum immunhistochemischen Nachweis in der vorliegenden Arbeit genutzt werden. Der gleiche Antikörper fand bereits in immunhistochemischen Analysen zum Beispiel im Rahmen der Krebsforschung Verwendung (Carbonell et al. 2013). Ein polyklonaler CD 44-Antikörper der eine entsprechende Reaktivität für menschliches und murines Gewebe aufwies, konnte zudem eingesetzt werden. Schlussendlich wurde ein monoklonaler aus der Maus gewonnener und gegen menschliches CD 90 gerichteter Antikörper verwendet.

Im Rahmen weiterer Vorversuche mussten jeweils optimale Bedingungen für die Inkubation mit den verwendeten Antikörpern ausgetestet werden. Die nachfolgende Tabelle 4 listet alle verwendeten Antikörper samt Inkubationsbedingungen auf. Alle Antikörper wurden bei Raumtemperatur angewendet. 
Tabelle 4: Liste der verwendeten Antikörper mit Inkubationsbedingungen

\begin{tabular}{|c|c|c|c|c|c|}
\hline Antikörper & $\begin{array}{c}\text { Klonal- } \\
\text { ität }\end{array}$ & Wirt & Reaktivität & $\begin{array}{c}\text { Inkubationsbedingungen } \\
\text { (Verdünnung / Inkubationszeit) }\end{array}$ & Herkunft \\
\hline $\begin{array}{l}\text { Macrophage } \\
\text { (HAM-56) }\end{array}$ & $\begin{array}{l}\text { mono- } \\
\text { klonal }\end{array}$ & Maus & unbestimmt & $1: 100 / 1$ Stunde & $\begin{array}{c}\text { Cell Marque, Rocklin, } \\
\text { USA }\end{array}$ \\
\hline CD $11 b$ & $\begin{array}{l}\text { mono- } \\
\text { klonal }\end{array}$ & $\begin{array}{l}\text { Kanin- } \\
\text { chen }\end{array}$ & Mensch & 1:100 / über Nacht & $\begin{array}{c}\text { Novus Biologicals, } \\
\text { Littleton, USA }\end{array}$ \\
\hline $\begin{array}{c}\text { Anti- } \\
\text { Neutrophil- } \\
\text { Elastase }\end{array}$ & $\begin{array}{l}\text { poly- } \\
\text { klonal }\end{array}$ & $\begin{array}{l}\text { Kanin- } \\
\text { chen }\end{array}$ & $\begin{array}{l}\text { Mensch, } \\
\text { Maus, Ratte }\end{array}$ & 1:50/ 1 Stunde & $\begin{array}{c}\text { Abcam, Cambridge, } \\
\text { England }\end{array}$ \\
\hline $\begin{array}{c}\text { Kollagen Typ } \\
\text { I }\end{array}$ & $\begin{array}{l}\text { poly- } \\
\text { klonal }\end{array}$ & $\begin{array}{l}\text { Kanin- } \\
\text { chen }\end{array}$ & Mensch & 1:100 / über Nacht & $\begin{array}{c}\text { Acris, Herford, } \\
\text { Deutschland }\end{array}$ \\
\hline $\begin{array}{l}\text { Kollagen Typ } \\
\text { III }\end{array}$ & $\begin{array}{l}\text { poly- } \\
\text { klonal }\end{array}$ & $\begin{array}{l}\text { Kanin- } \\
\text { chen }\end{array}$ & $\begin{array}{l}\text { Mensch, } \\
\text { Maus, Ratte }\end{array}$ & 1:50 / über Nacht & $\begin{array}{l}\text { Acris, Herford, } \\
\text { Deutschland }\end{array}$ \\
\hline $\begin{array}{l}\text { Kollagen Typ } \\
\text { IV (CIV 22) }\end{array}$ & $\begin{array}{l}\text { mono- } \\
\text { klonal }\end{array}$ & Maus & unbestimmt & 1:100/ 1 Stunde & $\begin{array}{c}\text { Cell Marque, Rocklin, } \\
\text { USA }\end{array}$ \\
\hline $\begin{array}{l}\text { Kollagen Typ } \\
\text { XII }\end{array}$ & $\begin{array}{l}\text { poly- } \\
\text { klonal }\end{array}$ & $\begin{array}{l}\text { Kanin- } \\
\text { chen }\end{array}$ & $\begin{array}{l}\text { Mensch, } \\
\text { Maus }\end{array}$ & $1: 100 / 1$ Stunde & $\begin{array}{l}\text { Prof. Robert Burgeson, } \\
\text { Massachusetts General } \\
\text { Hospital, Charlestown, } \\
\text { USA }\end{array}$ \\
\hline CD 29 & $\begin{array}{l}\text { mono- } \\
\text { klonal }\end{array}$ & $\begin{array}{l}\text { Kanin- } \\
\text { chen }\end{array}$ & $\begin{array}{c}\text { Mensch, } \\
\text { Maus, Ratte }\end{array}$ & $1: 100 /$ über Nacht & $\begin{array}{c}\text { Abcam, Cambridge, } \\
\text { England }\end{array}$ \\
\hline $\mathrm{CD} 44$ & $\begin{array}{l}\text { poly- } \\
\text { klonal }\end{array}$ & $\begin{array}{l}\text { Kanin- } \\
\text { chen }\end{array}$ & $\begin{array}{c}\text { Mensch, } \\
\text { Maus, Ratte }\end{array}$ & 1:100 / über Nacht & $\begin{array}{c}\text { Abcam, Cambridge, } \\
\text { England }\end{array}$ \\
\hline CD 90 & $\begin{array}{l}\text { mono- } \\
\text { klonal }\end{array}$ & Maus & Mensch & 1:100 / über Nacht & $\begin{array}{c}\text { IBFB GmbH, Leipzig, } \\
\text { Deutschland }\end{array}$ \\
\hline
\end{tabular}

\subsection{Gegenfärben, Rehydrieren, Decken}

Nach der immunhistochemischen Färbung wurden die Präparate zunächst mit einer Hämalaunlösung (Meyer 1:4) gegengefärbt und anschließend in einem Färbeautomaten (Stainix Diapath, Martinengo, Italien) dehydriert (siehe Tabelle 5). Danach erfolgte die Behandlung mit einem Einbettmedium (Eukitt ${ }^{\circledR}$ quick-hardening mounting medium SigmaAldrich, St. Louis, USA). Unter Verwendung eines Deckglases (Cover Slips Menzel, Braunschweig, Deutschland) wurden die Proben für die anschließende lichtmikroskopische Untersuchung vorbereitet. 
Tabelle 5: Protokoll der Dehydrierung

\begin{tabular}{ccc}
\hline Abfolgeposition & Küvetteninhalt & Dauer der Behandlung \\
\hline eins & Ethanol (50\%) & 3 Minuten \\
zwei & Ethanol (60\%) & 3 Minuten \\
drei & Ethanol (80\%) & 3 Minuten \\
vier & Ethanol (90\%) & 3 Minuten \\
fünf & Ethanol (100\%) & 3 Minuten \\
sechs & Xylol & 3 Minuten \\
sieben & Xylol & 3 Minuten \\
\hline
\end{tabular}

\subsection{Hämatoxylin-Eosin (H.E.)-Färbung}

Die H.E.-Färbung wurde mit Hilfe eines Färbeautomaten (Stainix Diapath, Martinengo, Italien) vorgenommen. Hämalaunlösung nach Meyer 1:4 wurde durch vermengen von 3 Teilen Auqua dest. mit 1 Teil Hämalaun nach Meyer (HX093785 Merck, Darmstadt, Deutschland) hergestellt. Die 0,1\%ige Eosinlösung wurde durch Auffüllen von $1000 \mathrm{ml}$ Aqua dest. auf 1 g Eosin (E6003 Sigma-Aldrich, St. Louis, USA) angesetzt. Das Färbeprotokoll wird in Tabelle 6 aufgeführt. 
Tabelle 6: Protokoll für die H.E.-Färbung mit dem Färbeautomat Stainix

\begin{tabular}{ccc}
\hline Abfolgeposition & Küvetteninhalt & Dauer der Behandlung \\
\hline eins & Xylol & 5 Minuten \\
zwei & Ethanol $(100 \%)$ & 2 Minuten \\
drei & Ethanol $(80 \%)$ & 2 Minuten \\
vier & Aqua dest. & 2 Minuten \\
fünf & Hämalaun (Meyer 1:4) & 4 Minuten \\
sechs & Aqua dest. & 1 Minuten \\
sieben & fließend Wasser & 15 Minuten \\
acht & Eosin Y $(0,1 \%)$ & 7 Minuten \\
neun & Aqua dest. & 1 Minuten \\
zehn & Ethanol $(60 \%)$ & 1 Minuten \\
elf & Ethanol $(80 \%)$ & 1 Minuten \\
zwölf & Ethanol $(100 \%)$ & 2 Minuten \\
dreizehn & Xylol & 3 Minuten
\end{tabular}

\subsection{Durchführung}

Alle Versuche mit spezifischen Antikörpern wurden jeweils drei mal pro Patient wiederholt, um die Reproduzierbarkeit der Ergebnisse sicherzustellen. Der Spezifitätsnachweis durchgeführter immunhistochemischer Reaktionen konnte im Rahmen jedes einzelnen Versuchs durch sogenannte Kontrollreaktionen erbracht werden. Hierbei wurden alle Arbeitsschritte, mit Ausnahme der Inkubation des primären Antikörpers gemäß des Protokolls für die Verwendung des Dako REAL ${ }^{\text {TM }}$ Detection Sytem Alkaline Phosphatase/RED Rabbit/ Mouse Kits durchgeführt. Alle Kontrollen fielen negativ aus. 


\section{ERGEBNISSE}

\subsection{Allgemeine Qualität der Präparate}

Da die Präparate von Zähnen stammen, die im Zuge der zahnärztlichen Extraktion gewonnen wurden, müssen qualitative Einschränkungen in Kauf genommen werden. Im Rahmen der üblichen Extraktionstechniken sind mechanische Krafteinwirkungen auf den Zahnhalteapparat nicht zu vermeiden, wobei letztendlich der Zahn durch Abreißen des parodontalen Faserapparates aus seiner knöchernen Alveole entfernt wird. Durch diese Manipulationen wird die strukturelle Unversehrtheit des parodontalen Gewebes verletzt. Die Folge sind Risse innerhalb des PDL-Gewebes einiger Proben.

Zudem enthalten die so gewonnenen Präparate in der Regel keinen Knochen jedoch können in einigen Fällen Teile der Alveole dem Desmodont extrahierter Zähne anheften. Gegenstand der Untersuchung ist somit im Wesentlichen der dem Zement zugewandte Teil des PDLs. Dieser wird beispielhaft durch Abbildung 3 in der Übersicht dargestellt. Abbildung 4 zeigt einen vergrößerten Ausschnitt dieser Übersicht. Alle folgenden Abbildungen von Präparaten der vorliegenden Arbeit weisen die gleiche prinzipielle Orientierung auf. Von oben nach unten sind fortwährend die Gewebe Wurzeldentin, Wurzelzement und Desmodont angeordnet, wobei das Hauptaugenmerk auf das PDL gerichtet sein wird. 


\section{Ergebnisse}

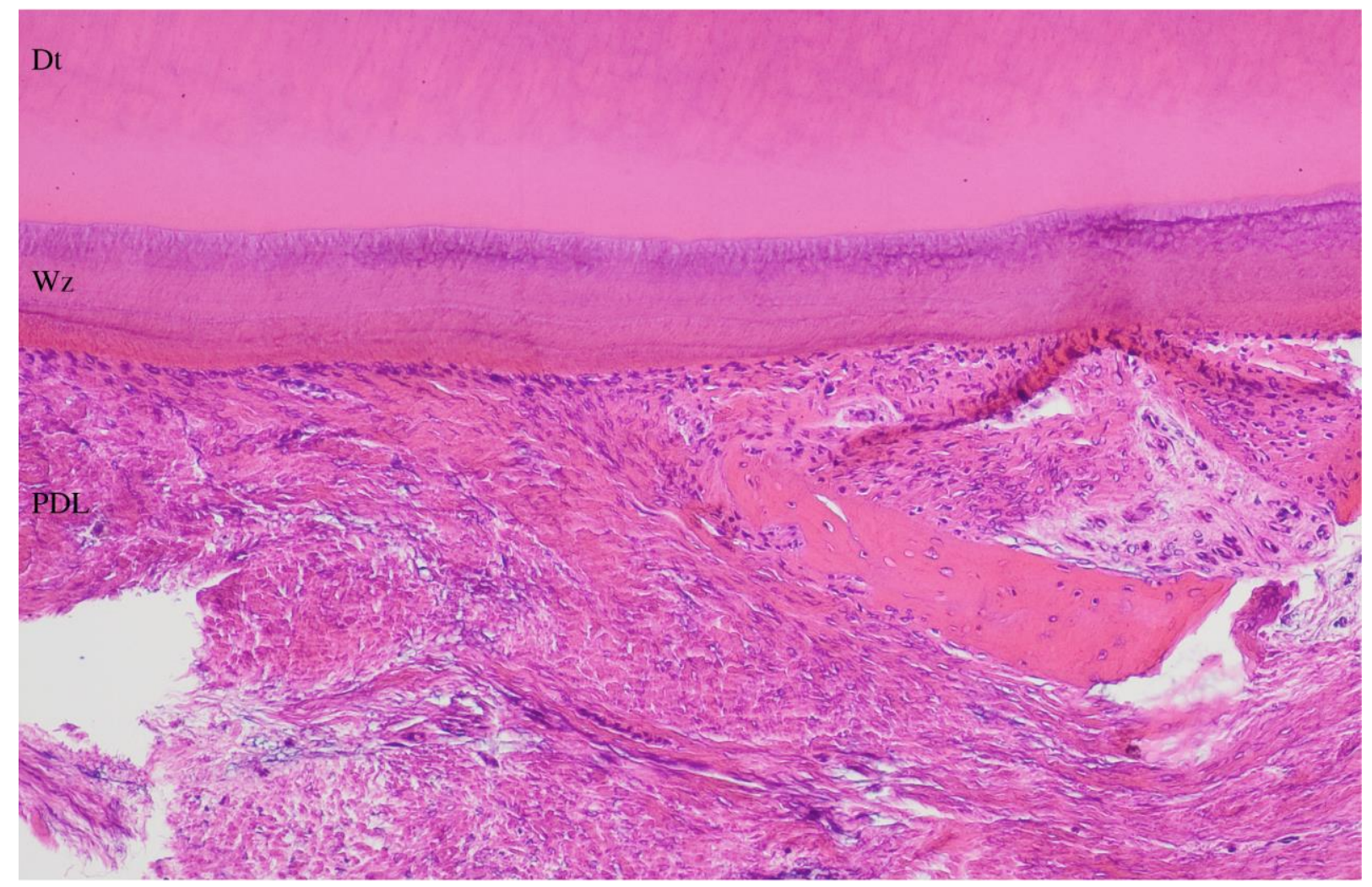

Abbildung 3: Übersicht des menschlichen Zahnhalteapparates; H.E.-Färbung; Vergrößerung: 10fach; „Dt“ = Dentin; ,WZ“ = Wurzelzement; ,PDL“ = parodontales Ligamentgewebe.

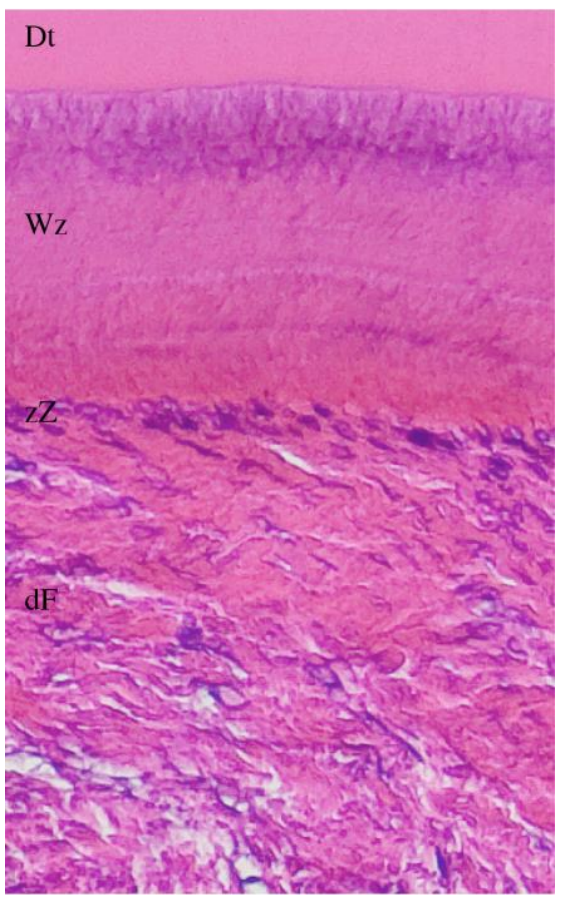

Abbildung 4: Ausschnitt aus Abbildung 3; Schematische Darstellung des dem Zement zugewandten Teils des Zahnhalteapparates der untersuchten Proben; H.E.-Färbung; Vergrößerung: 40fach; „Dt“ = Dentin; „Wz“ = Wurzelzement; ,,ZZ“ = zementnahe Zellen/Zementoblastenzellschicht; „,dF“ = desmodontaler Faserapparat mit überwiegend Fibroblasten. 


\subsection{Der immunhistochemische Nachweis von Entzündungsmarkern im klinisch gesunden und erkranktem PDL}

\subsubsection{Immunhistochemischer Nachweis des Antikörpers Makrophage (HAM-56)}

Innerhalb des untersuchten Probandenguts zeigten sich bei klinisch parodontal gesunden Patienten vereinzelt schwach positive Entzündungszellen, jedoch nicht in dem Ausmaß wie bei klinisch parodontal erkrankten Patienten. Diese wiesen in nahezu allen Proben schwach positive Entzündungszellen auf (siehe Abbildungen 5A bis C). Beide Patientengruppen zeigten zudem positiv gefärbte Endothelzellen (siehe Abbildung 5D am Beispiel eines parodontal erkrankten Patienten). Tabelle 7 listet eine patientenbezogene Auswertung der Versuchsergebnisse auf.

Tabelle 7: Nachweis des Antikörpers HAM-56; ,,+“ $=$ positiv; , $(+)^{“}=$ schwach positiv; , ,-“ $=$ negativ; ,n. b. $.^{“}=$ nicht beurteilbar.

\begin{tabular}{cccc}
\hline klinischer partodontaler Befund & Patient & Entzündungszellen & Endothel \\
\hline krank & K1 & $(+)$ & + \\
krank & K2 & $(+)$ & + \\
krank & K3 & $(+)$ & n.b. \\
gesund & G1 & - & n.b. \\
gesund & G2 & - & n.b. \\
gesund & G3 & $(+)$ & $(+)$ \\
\hline
\end{tabular}



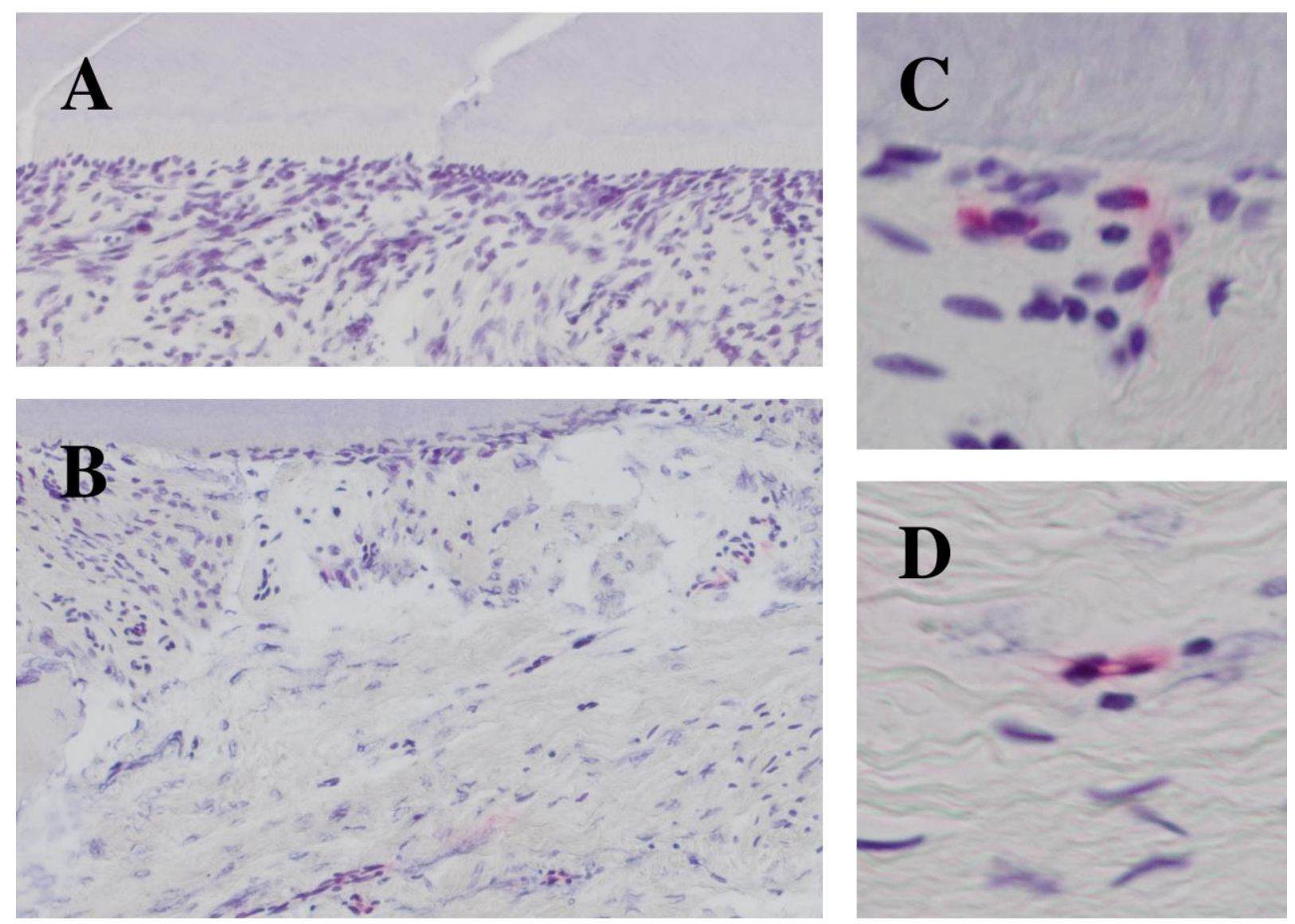

Abbildung 5: Immunhistochemische HAM-56-Färbung. A: Ausschnitt des Zahnhalteapparates eines klinisch parodontal gesunden Patienten; Es sind keine positiven Entzündungszellen vorhanden; Vergrößerung: 10fach. B: Ausschnitt des Zahnhalteapparates eines klinisch parodontal erkrankten Patienten; Übersicht mit positiven Entzündungszellen und positivem Endothel; Vergrößerung: 10fach. C: Ausschnitt des Zahnhalteapparates eines klinisch parodontal erkrankten Patienten; schwach positive Entzündungszellen; Vergrößerung: 40fach. D: Ausschnitt des Zahnhalteapparates eines klinisch parodontal erkrankten Patienten; positive Endothelzellen; Vergrößerung: 40fach.

\subsubsection{Immunhistochemischer Nachweis des Antikörpers CD 11b (Mac-1)}

Der immunhistochemische Nachweis zeigte im Zahnhalteapparat parodontal gesunder Patienten bis auf eine Ausnahme keine CD 11b-positiven Zellen (siehe Abbildung 6A). Hier lagen neben negativen auch schwach positive Proben vor. Klinisch parodontal erkrankte Patienten wiesen hingegen immer CD 11b-positive Entzündungszellen auf, die gehäuft zementnah und in Gruppen anzutreffen waren (siehe Abbildungen 6B und C). 
Tabelle 8: Nachweis des Antikörpers CD 11b; ,,“" = positiv; ,, $(+)^{“ “}=$ schwach positiv; ,,“" = negativ.

\begin{tabular}{ccc}
\hline klinischer partodontaler Befund & Patient & Entzündungszellen \\
\hline krank & $\mathrm{K} 1$ & + \\
krank & $\mathrm{K} 2$ & + \\
krank & $\mathrm{K} 3$ & + \\
gesund & $\mathrm{G} 1$ & - \\
gesund & $\mathrm{G} 2$ & $(+)$ \\
gesund & $\mathrm{G} 3$ & - \\
\hline
\end{tabular}
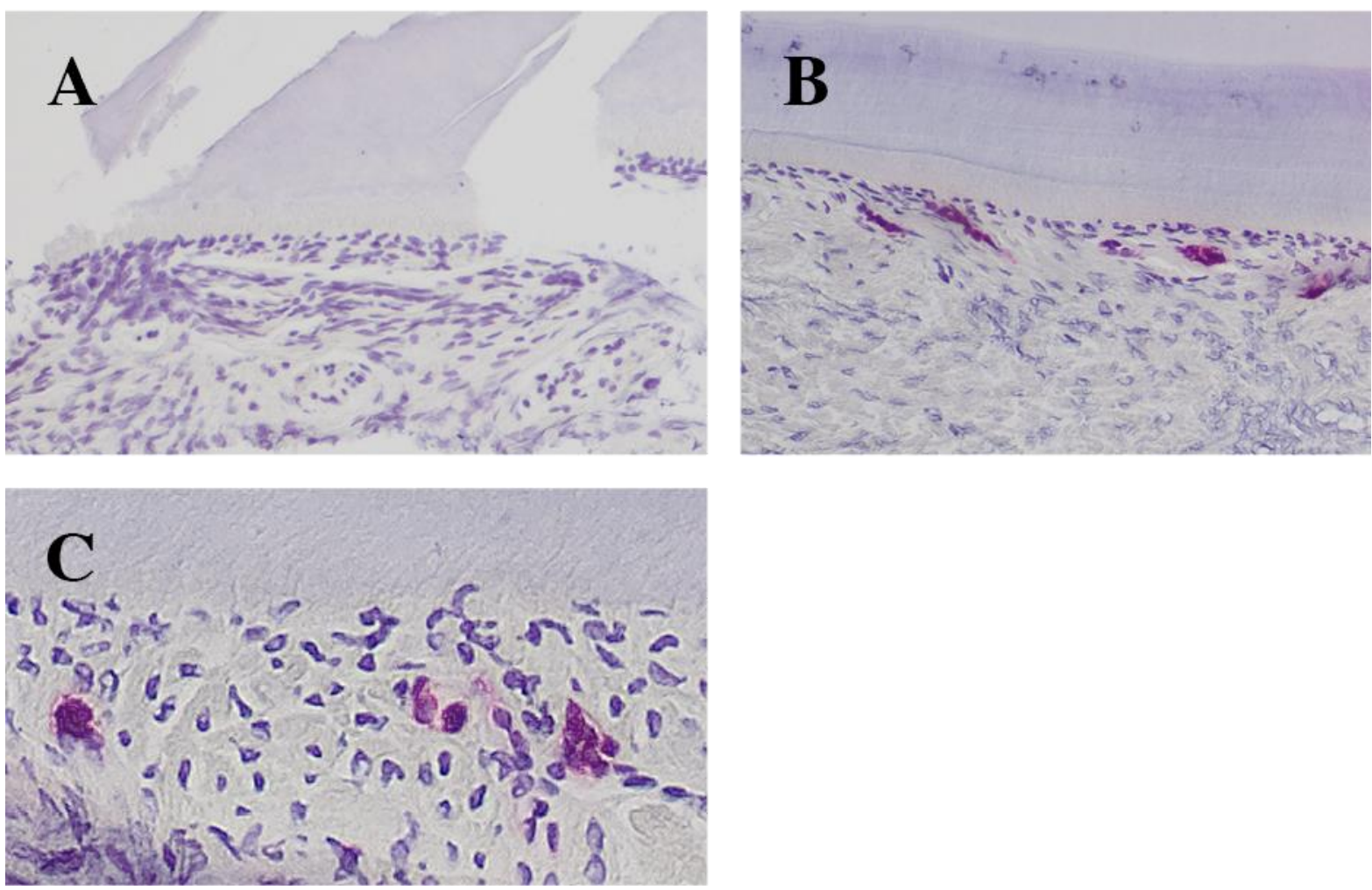

Abbildung 6: Immunhistochemische CD 11b-Färbung. A: Ausschnitt des Zahnhalteapparates eines klinisch parodontal gesunden Patienten; Es sind keine positiven Entzündungszellen vorhanden; Vergrößerung: 10fach. B: Ausschnitt des Zahnhalteapparates eines klinisch parodontal erkrankten Patienten; Übersicht positiver Entzündungszellen; Vergrößerung: 10fach. C: Ausschnitt des Zahnhalteapparates eines klinisch parodontal erkrankten Patienten; Positive Entzündungszellen; Vergrößerung: 40fach. 


\subsubsection{Immunhistochemischer Nachweis des Antikörpers Anti-Neutrophil-Elastase}

Parodontal gesunde Patienten wiesen entweder keine oder vereinzelt schwach AntiNeutrophil-Elastase-positive Entzündungszellen auf (siehe Abbildung 7A). Im Gegensatz hierzu zeigten sich bei allen paradontal erkrankten Patienten prinzipiell mehr und stärker gefärbte Entzündungszellen (siehe Abbildung 7B). Diese waren jedoch auch nur in geringer Anzahl vorhanden. Bei allen Proben war eine schwache Hintergrundfärbung festzustellen.

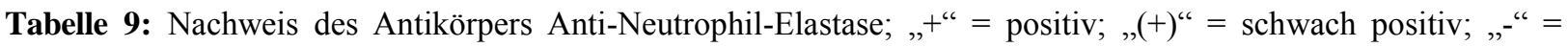
negativ; EZM = extrazelluläre Matrix.

\begin{tabular}{cccc}
\hline klinischer partodontaler Befund & Patient & Entzündungszellen & EZM \\
\hline krank & K1 & + & + \\
krank & K2 & + & + \\
krank & K3 & $(+)$ & + \\
gesund & G1 & $(+)$ & $(+)$ \\
gesund & G2 & $(+)$ & $(+)$ \\
gesund & G3 & - & $(+)$ \\
\hline
\end{tabular}
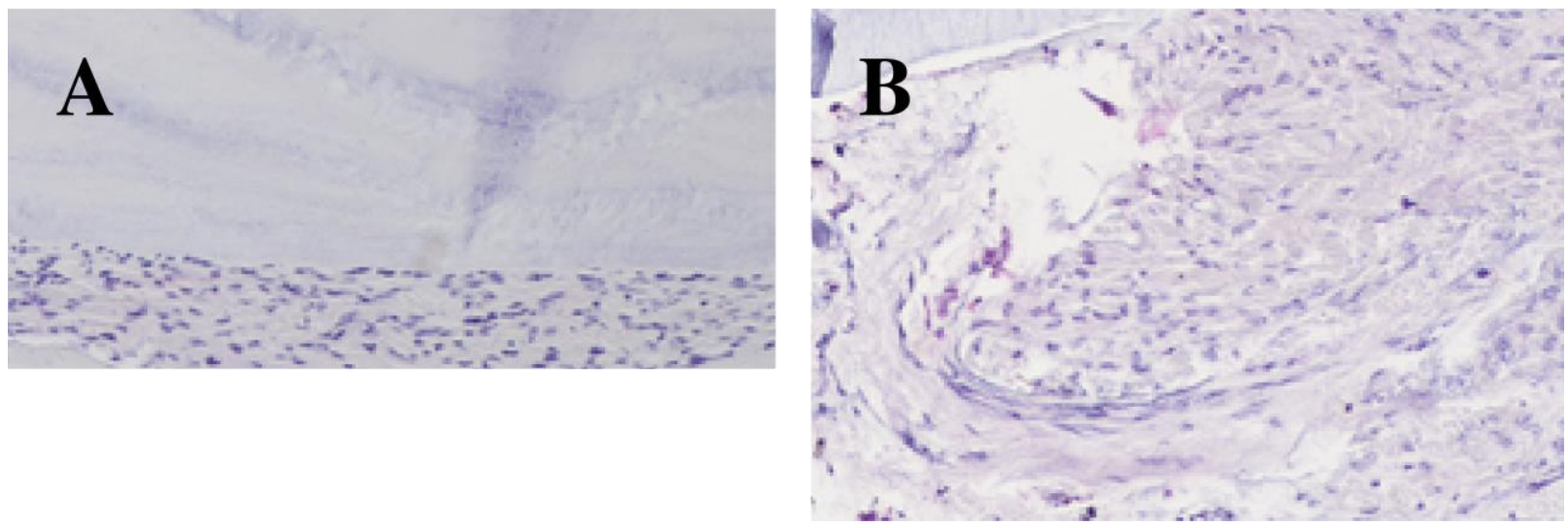

Abbildung 7: Immunhistochemische Anti-Neutrophil-Elastase-Färbung. A: Ausschnitt des Zahnhalteapparates eines klinisch parodontal gesunden Patienten; Es sind keine positiven Entzündungszellen vorhanden; Vergrößerung: 10fach. B: Ausschnitt des Zahnhalteapparates eines klinisch parodontal erkrankten Patienten; Übersicht mit wenigen positiven Entzündungszellen; Vergrößerung: $10 \mathrm{fach}$. 


\subsection{Histologische Charakterisierung von Fibroblasten und zementnahen} Zellen im klinisch gesunden und erkranktem PDL

\subsubsection{Charakterisierung von Fibroblasten im PDL}

Im Vergleich zwischen parodontal gesunden und parodontal erkrankten Patienten wiesen die Fibroblasten des untersuchten Probandenguts in der H.E.-Färbung keine signifikanten Unterschiede auf. Es zeigte sich eine prinzipiell parallele Orientierung der Fibroblasten zum gewellt erscheinenden parodontalen Faserverlauf. Die Form der Fibroblastenzellkerne, die in Längsrichtung angeschnitten wurden, stellten sich als charakteristisch länglich flach bis oval dar (siehe Abbildung 8A und B). Fibroblastenzellkerne hierzu senkrecht verlaufender parodontaler Faserbündel wiesen in Querrichtung angeschnitten eine rundlich bis leicht ovale Form auf (siehe Abbildung 8C und D). Tendenziell waren mehr Zellen im parodontal gesunden Gewebe anzutreffen, wobei deren Kerne vergrößert erschienen.
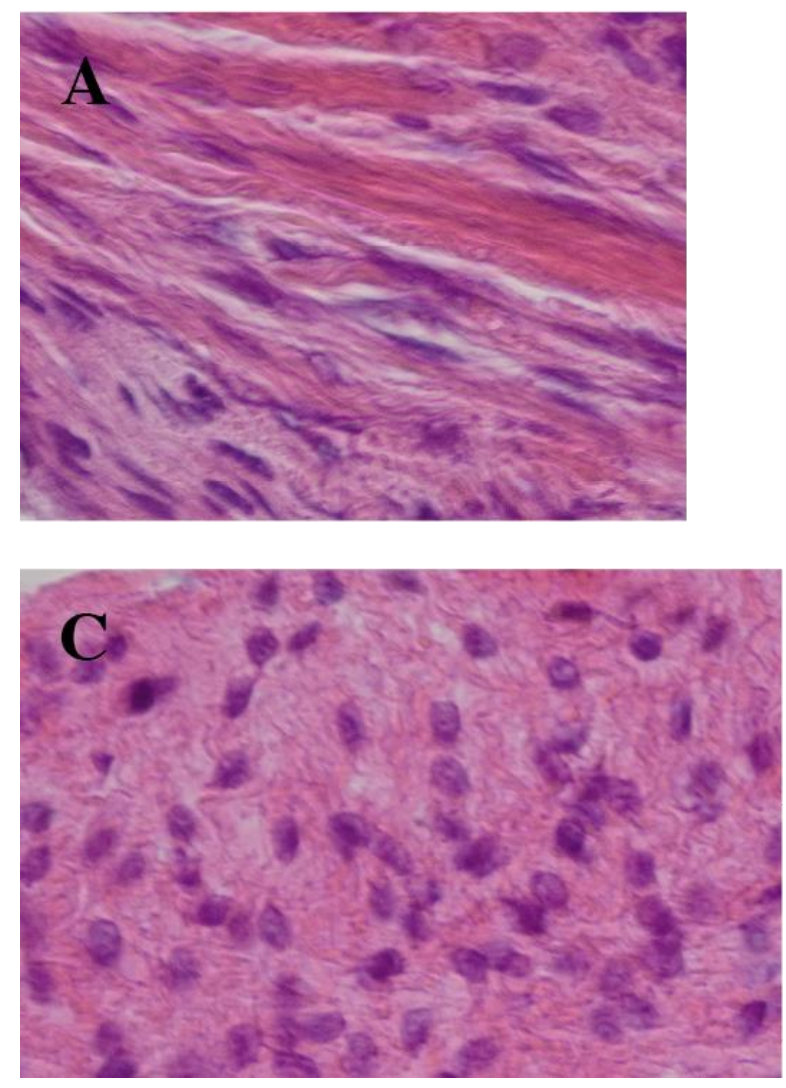
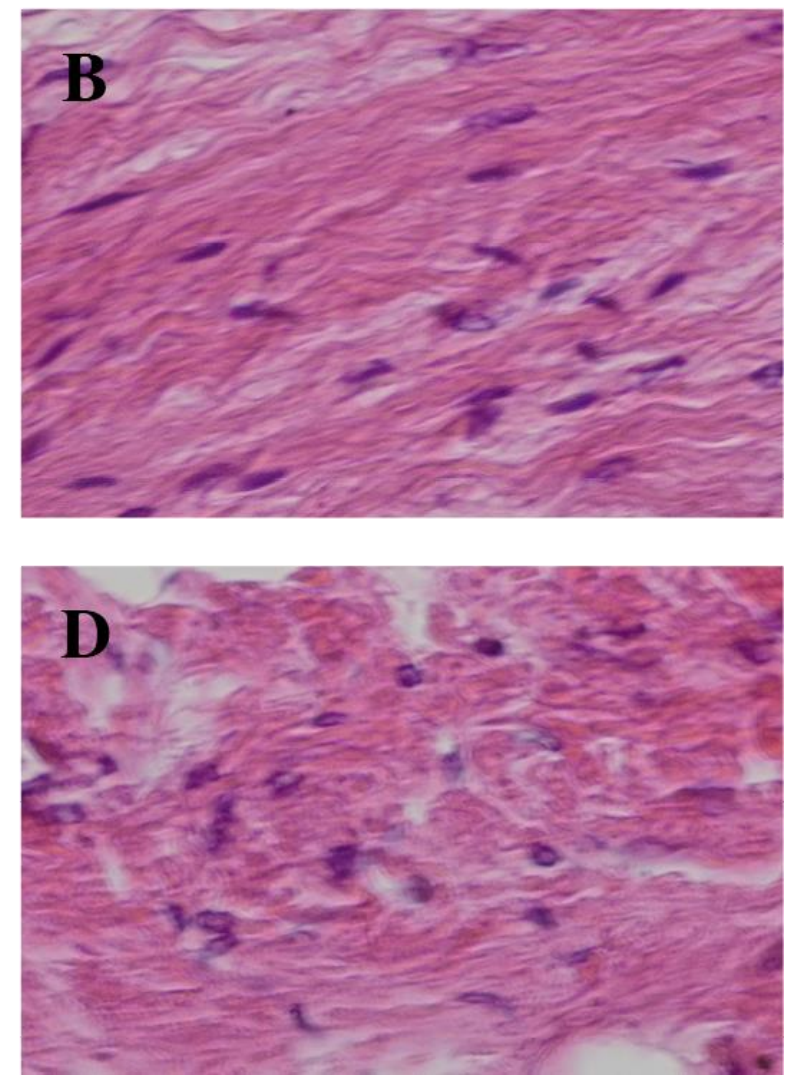

Abbildung 8: Charakterisierung von Fibroblastenzellkernen; H.E.-Färbung. A: Fibroblasten eines parodontal gesunden Patienten; in Längsrichtung angeschnitten; länglich flach bis ovale Zellkernform; 40fach. B: Fibroblasten eines parodontal erkrankten Patienten; in Längsrichtung angeschnitten; länglich flach bis ovale Zellkernform; 40fach. C: Fibroblasten eines parodontal gesunden Patienten; in Querrichtung angeschnitten; rundlich bis leicht ovale Zellkernform; 40fach. D: Fibroblasten eines parodontal erkrankten Patienten; in Querrichtung angeschnitten; rundlich bis leicht ovale Zellkernform; 40fach. 


\subsubsection{Charakterisierung von zementnahen Zellen im PDL}

Eine charakteristische Form der Kerne von zementnahen Zellen war nicht festzustellen. Vielmehr zeigte sich eine vielgestaltige Formgebung bei parodontal gesunden und erkrankten Patienten. Die Zellkerne variierten von einer länglich flach bis ovalen (siehe Abbildung 9A und B) zu einer länglich ovalen bis rundlichen Form (siehe Abbildung 9C und D). Im Allgemeinen zeigte sich jedoch im Vergleich zu Fibroblasten eine stärkere Färbung der Kerne zementnaher Zellpopulationen (siehe Abbildung 9E).
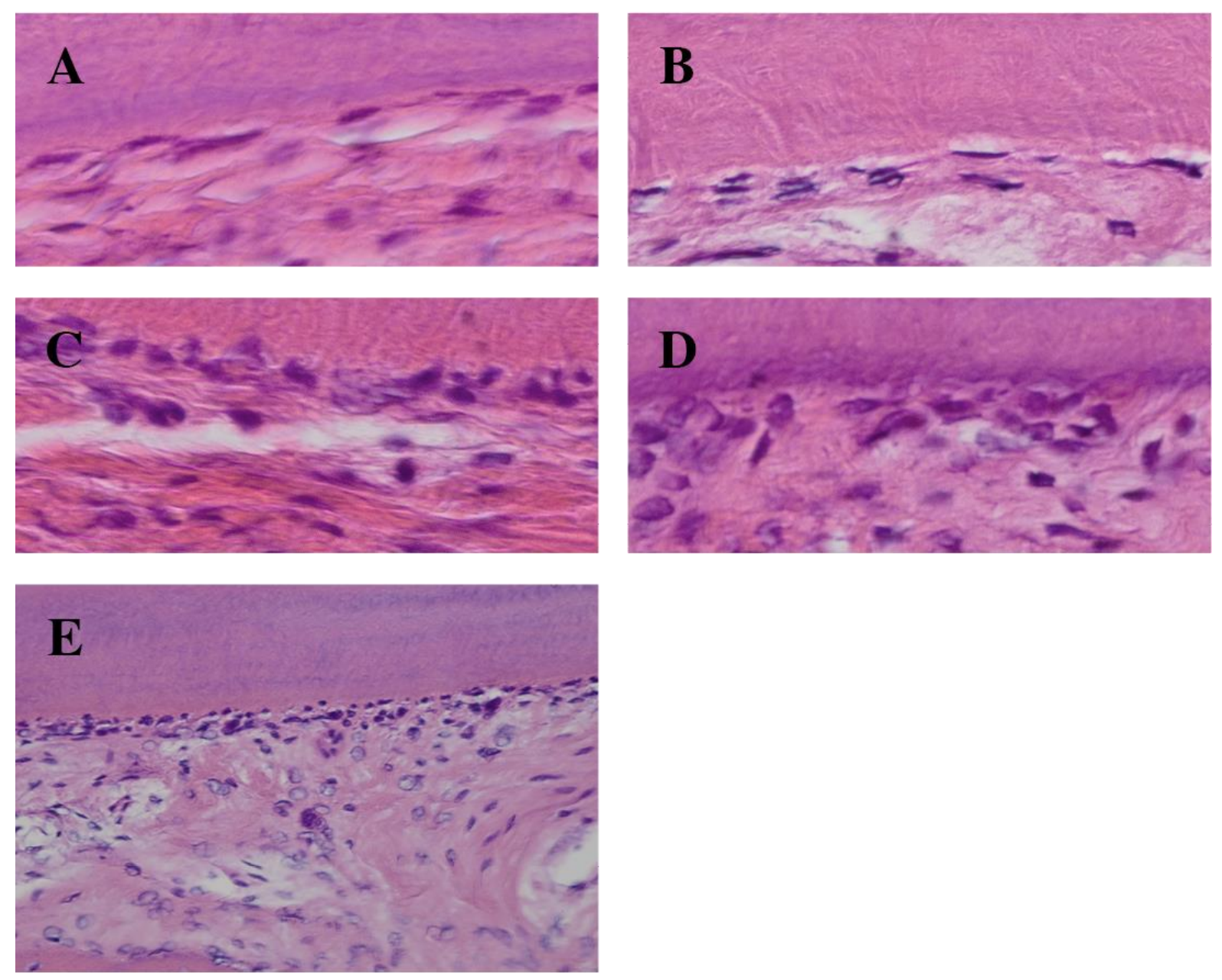

Abbildung 9: Charakterisierung von Zellkernen zementnaher Zellen; H.E.-Färbung. A: zementnahe Zellen eines parodontal gesunden Patienten; länglich flach bis ovale Form; 40fach. B: zementnahe Zellen eines parodontal erkrankten Patienten; länglich flach bis ovale Form; 40fach. C: zementnahe Zellen eines parodontal gesunden Patienten; länglich ovale bis rundliche Form; 40fach. D: zementnahe Zellen eines parodontal erkrankten Patienten; länglich ovale bis rundliche Form; 40fach; E: Übersicht; im Vergleich zu Fibroblasten stärker angefärbte Zellkerne zementnaher Zellen; 10fach. 


\subsection{Der immunhistochemische Nachweis von Kollagenen der EZM im klinisch gesunden und erkranktem PDL}

\subsubsection{Immunhistochemischer Nachweis von Kollagen Typ I}

Der Nachweis von Kollagen Typ I des Zahnhalteapparates wies immunhistochemisch keine signifikanten Unterschiede auf und war bei allen Patienten unabhängig vom klinischen parodontalen Befund vergleichbar. Es zeigte sich eine homogene positive Färbung des Dentins, Zements und der Faserbündel im PDL (siehe Abbildungen 10A und B).

Tabelle 10: Nachweis des Antikörpers Kollagen Typ I; , ${ }^{*} “=$ positiv; EZM = extrazelluläre Matrix.

\begin{tabular}{ccc}
\hline klinischer partodontaler Befund & Patient & EZM \\
\hline krank & $\mathrm{K} 1$ & + \\
krank & $\mathrm{K} 2$ & + \\
krank & $\mathrm{K} 3$ & + \\
gesund & $\mathrm{G} 1$ & + \\
gesund & $\mathrm{G} 2$ & + \\
gesund & $\mathrm{G} 3$ & + \\
\hline
\end{tabular}
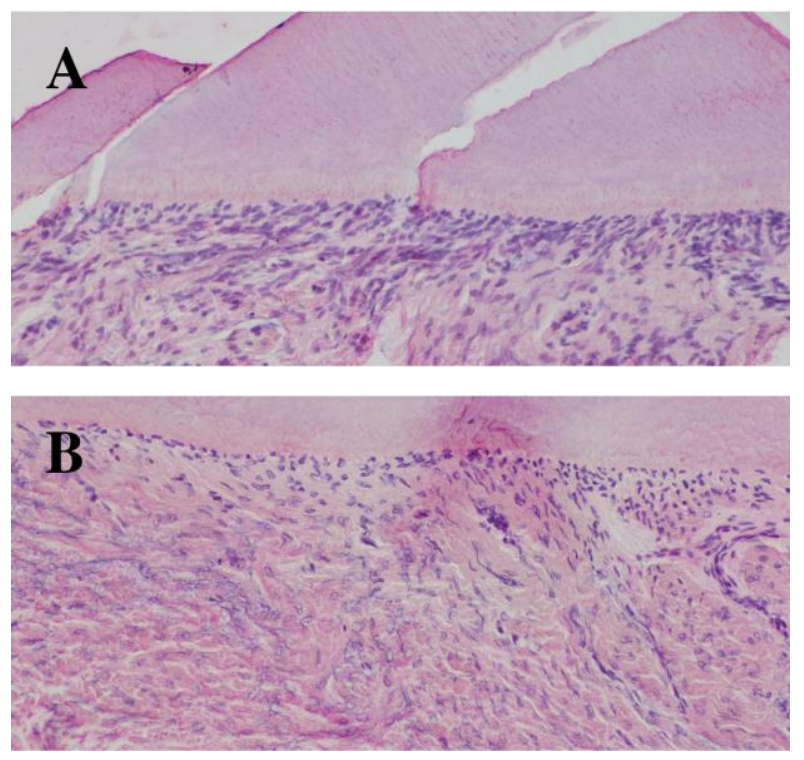

Abbildung 10: Immunhistochemische Kollagen Typ I-Färbung. A: Ausschnitt des Zahnhalteapparates eines klinisch parodontal gesunden Patienten; Homogene Färbung im PDL, Zement und Dentin; Vergrößerung: 10fach. B: Ausschnitt des Zahnhalteapparates eines klinisch parodontal erkrankten Patienten; Homogene Färbung im PDL, Zement und Dentin; Vergrößerung: 10fach. 


\subsubsection{Immunhistochemischer Nachweis von Kollagen Typ III}

Immunhistochemisch stellte sich der Nachweis von Kollagen Typ III in Bezug auf den parodontalen Befund als vergleichbar dar. Sowohl klinisch parodontal gesunde als auch erkrankte Patienten wiesen eine schwache Färbung der EZM im PDL auf (siehe Abbildung 11A und B). Im Zement und Dentin zeigte sich keine positive Färbung.

Tabelle 11: Nachweis des Antikörpers Kollagen Typ III; „(+)“ = schwach positiv; EZM = extrazelluläre Matrix.

\begin{tabular}{ccc}
\hline klinischer partodontaler Befund & Patient & EZM \\
\hline krank & K1 & $(+)$ \\
krank & K2 & $(+)$ \\
krank & K3 & $(+)$ \\
gesund & G1 & $(+)$ \\
gesund & G2 & $(+)$ \\
gesund & G3 & $(+)$ \\
\hline
\end{tabular}
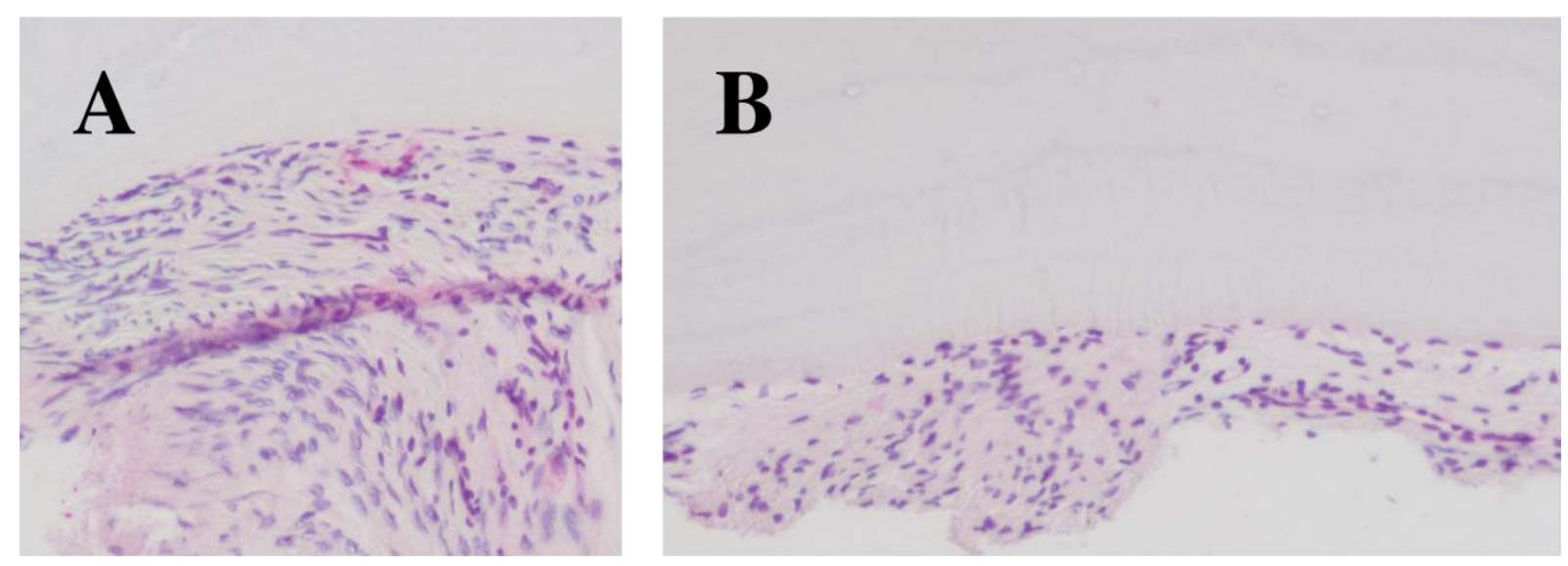

Abbildung 11: Immunhistochemische Kollagen Typ III-Färbung. Homogene schwach positive Färbung im PDL; A: Ausschnitt des Zahnhalteapparates eines klinisch parodontal gesunden Patienten; Übersicht der gefärbten extrazellulären Matrix; Vergrößerung: 10fach. B: Ausschnitt des Zahnhalteapparates eines klinisch parodontal erkrankten Patienten; Übersicht der gefärbten extrazellulären Matrix; Vergrößerung: $10 \mathrm{fach}$. 


\subsubsection{Immunhistochemischer Nachweis von Kollagen Typ IV}

Der Nachweis von Kollagen Typ IV innerhalb des untersuchten Probandenguts beschränkte sich auf die Basalmembran angeschnittener Blutgefäße. Prinzipiell fiel ein reiches Vorkommen an Blutgefäßen auf, wobei Gefäße der Endstrombahn gehäuft in „kleiner“ und „mittlerer“ Größe im zementnahen und mittleren Bereich anzutreffen waren. Hierbei zeigte sich bei allen Patienten unabhängig vom klinischen parodontalen Befund ein vergleichbares Bild an Blutgefäßen bezüglich Anzahl, Größe und Verteilung (siehe Abbildung 12A bis D).
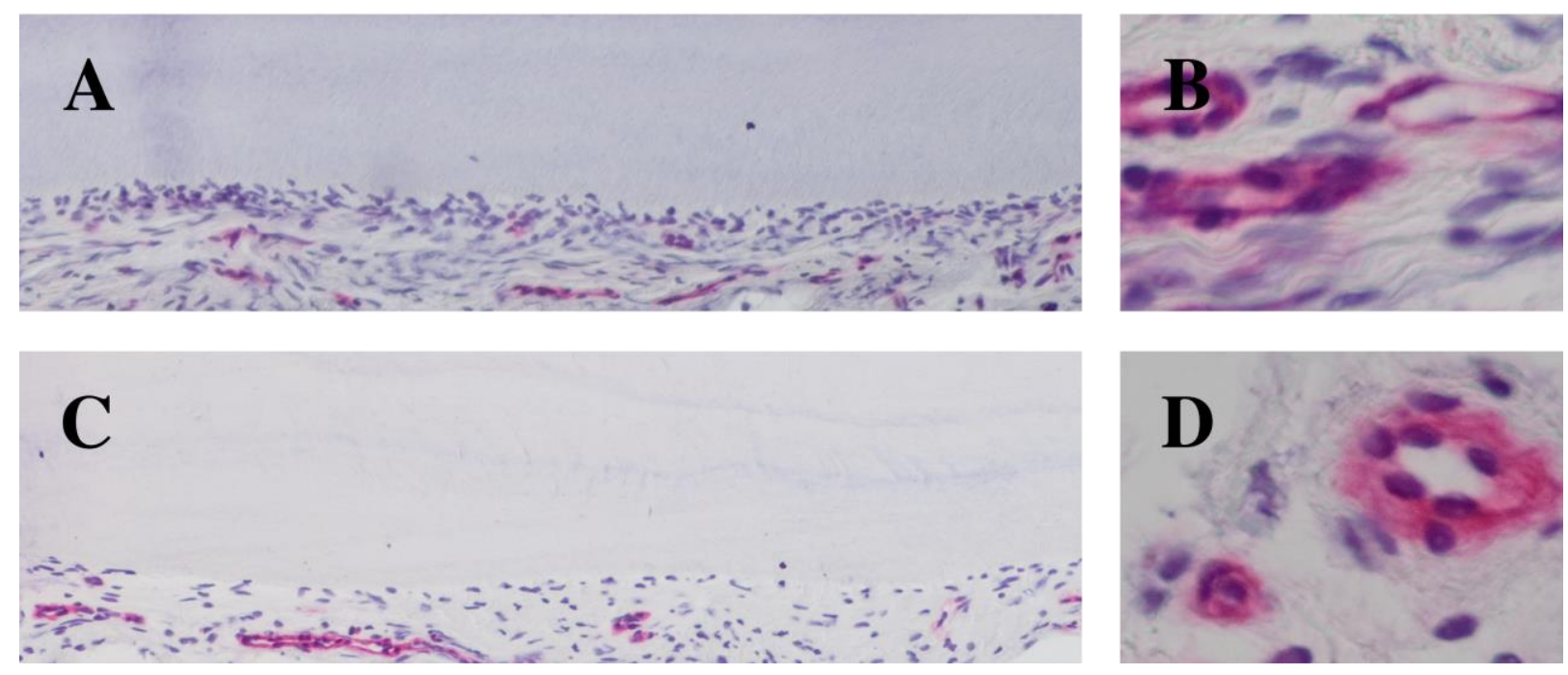

Abbildung 12: Immunhistochemische Kollagen Typ IV-Färbung. A: Ausschnitt des Zahnhalteapparates eines klinisch parodontal gesunden Patienten; Übersicht angefärbter Endothelzellen; Vergrößerung: 10fach. B: Endothel des Zahnhalteapparates eines klinisch parodontal gesunden Patienten; Vergrößerung: 40fach. C: Ausschnitt des Zahnhalteapparates eines klinisch parodontal erkrankten Patienten; Übersicht angefärbter Endothelzellen; Vergrößerung: 10fach. D: Endothel des Zahnhalteapparates eines klinisch parodontal erkrankten Patienten; Vergrößerung: 40fach.

\subsubsection{Immunhistochemischer Nachweis von Kollagen Typ XII}

Das Vorkommen von Kollagen Typ XII des Zahnhalteapparates war immunhistochemisch bei allen Patienten unabhängig vom klinischen parodontalen Befund vergleichbar (siehe Abbildungen 13A und C). Bei allen Proben lag eine Färbung nahezu aller Anteile des PDLGewebes vor, wobei tendenziell zementnahe Anteile stärker gefärbt erschienen. Zahnhartgewebe blieben ungefärbt. Zudem zeigte sich eine Expression im Bereich des Endothels (siehe Abbildungen 13B und D). 
Tabelle 12: Nachweis des Antikörpers Kollagen Typ XII; „,““ = positiv; „n. b.“ = nicht beurteilbar; EZM = extrazelluläre Matrix

\begin{tabular}{cccc}
\hline klinischer partodontaler Befund & Patient & EZM & Endothel \\
\hline krank & K1 & + & + \\
krank & K2 & + & + \\
krank & K3 & + & + \\
gesund & G1 & + & + \\
gesund & G2 & + & n.b. \\
gesund & G3 & + & n.b. \\
\hline
\end{tabular}
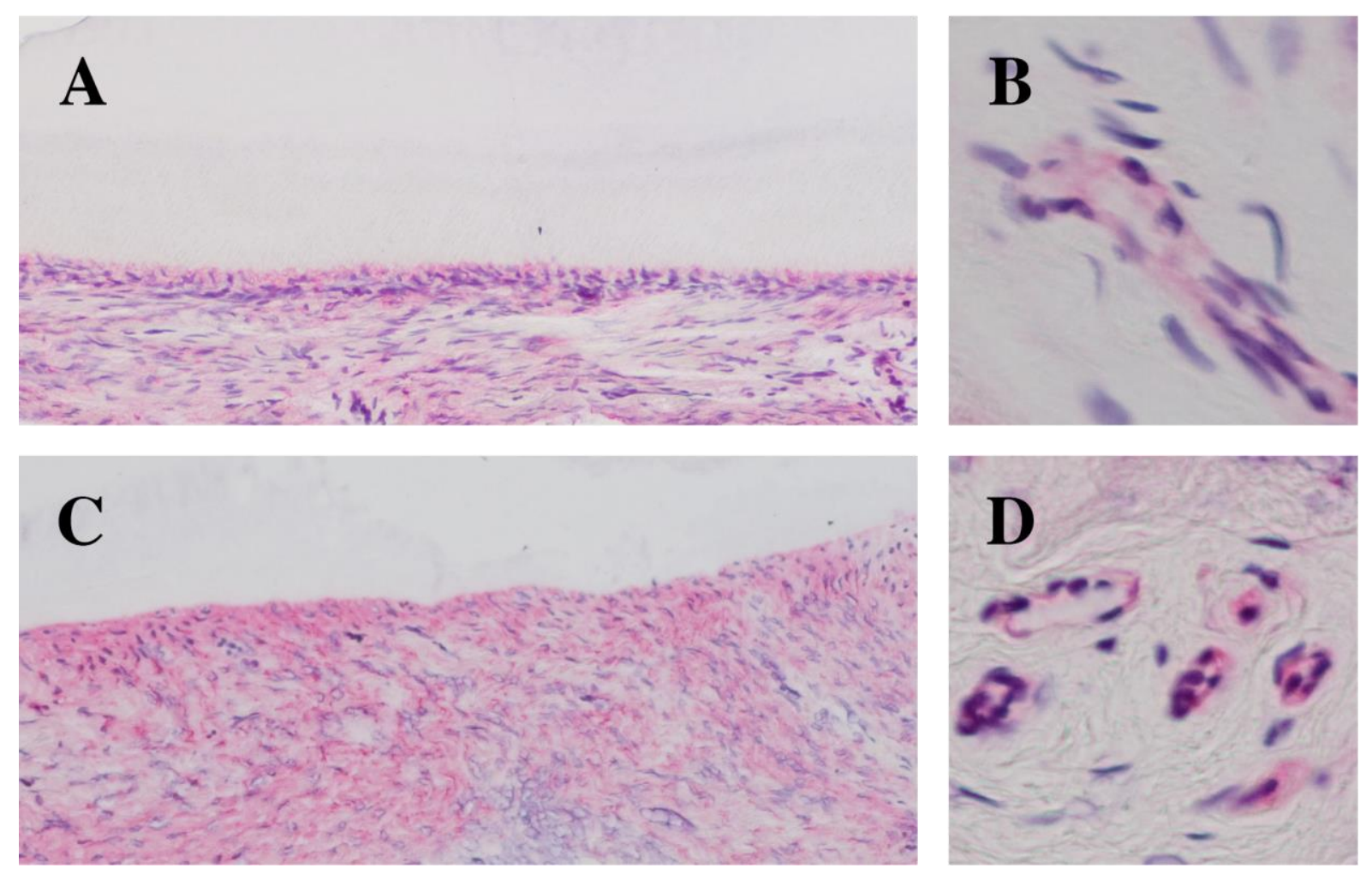

Abbildung 13: Immunhistochemische Kollagen Typ XII-Färbung. A: Ausschnitt des Zahnhalteapparates eines klinisch parodontal gesunden Patienten; Übersicht der gefärbten EZM; Vergrößerung: 10fach. B: Endothel des Zahnhalteapparates eines klinisch parodontal gesunden Patienten; Vergrößerung: 40fach. C: Ausschnitt des Zahnhalteapparates eines klinisch parodontal erkrankten Patienten; Übersicht der gefärbten EZM; Vergrößerung: 10fach. D: Endothel des Zahnhalteapparates eines klinisch parodontal erkrankten Patienten; Vergrößerung: 40 fach. 


\subsection{Der immunhistochemische Nachweis von ausgesuchten}

\section{Stammzellmarkern/Adhäsionsmolekühlen im klinisch gesunden und erkranktem PDL}

\subsubsection{Immunhistochemischer Nachweis von CD 29 (Integrin beta 1)}

Der immunhistochemische Nachweis des Antikörpers CD 29 wies keine quantifizierbaren Ergebnisse bezüglich des klinischen parodontalen Befundes auf (siehe Übersicht Abbildung 14A und B). Innerhalb des untersuchten Probandenguts zeigten sich sowohl bei parodontal gesunden als auch bei parodontal erkrankten Patienten CD 29-positive zementnahe Zellen (siehe Abbildungen 14C und D), Fibroblasten (siehe Abbildungen 14E und F) und Endothelzellen (siehe Abbildungen 14G und H). Besondere Auffälligkeiten bezüglich der Verteilung waren nicht festzustellen. Die Quantität angefärbter Zellpopulationen schwankte innerhalb der untersuchten Stichproben.

Tabelle 13: Nachweis des Antikörpers CD 29; „,““= positiv; „, $(+)^{“}=$ schwach positiv; ,,““ = negativ; , „n. b. “ = nicht beurteilbar; EZM = extrazelluläre Matrix.

\begin{tabular}{|c|c|c|c|c|c|}
\hline $\begin{array}{c}\text { klinischer } \\
\text { partodontaler Befund }\end{array}$ & Patient & $\begin{array}{c}\text { zementnahe } \\
\text { Zellen }\end{array}$ & Fibroblasten & Endothel & EZM \\
\hline krank & $\mathrm{K} 1$ & + & + & + & $(+)$ \\
\hline krank & $\mathrm{K} 2$ & $(+)$ & $(+)$ & + & - \\
\hline krank & K3 & $(+)$ & $(+)$ & n.b. & - \\
\hline gesund & G1 & + & $(+)$ & + & - \\
\hline gesund & $\mathrm{G} 2$ & + & n.b. & n.b. & - \\
\hline gesund & G3 & + & + & $(+)$ & - \\
\hline
\end{tabular}



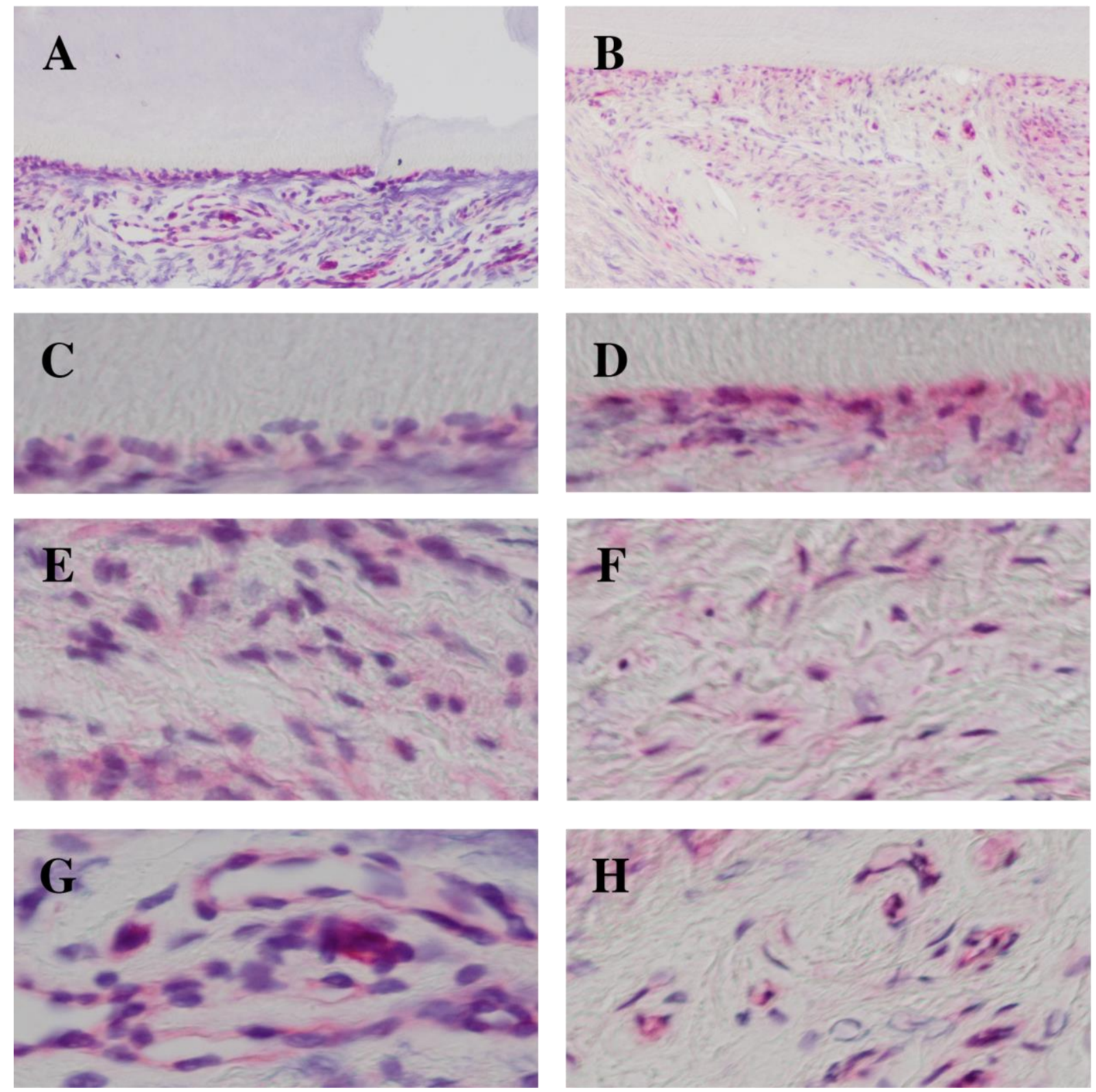

Abbildung 14: Immunhistochemische CD 29-Färbung. A: Ausschnitt des Zahnhalteapparates eines klinisch parodontal gesunden Patienten; Übersicht; Vergrößerung: 10fach. B: Ausschnitt des Zahnhalteapparates eines klinisch parodontal erkrankten Patienten; Übersicht; Vergrößerung: 10fach. C: Ausschnitt des Zahnhalteapparates eines klinisch parodontal gesunden Patienten; CD 29-positive zementnahe Zellen; Vergrößerung: 40fach. D: Ausschnitt des Zahnhalteapparates eines klinisch parodontal erkrankten Patienten; CD 29-positive zementnahe Zellen; Vergrößerung: 40fach. E: Ausschnitt des Zahnhalteapparates eines klinisch parodontal gesunden Patienten; CD 29-positive Fibroblasten; Vergrößerung: 40fach. F: Ausschnitt des Zahnhalteapparates eines klinisch parodontal erkrankten Patienten; CD 29-positive Fibroblasten; Vergrößerung: 40fach. G: Ausschnitt des Zahnhalteapparates eines klinisch parodontal gesunden Patienten; CD 29-positive Endothelzellen; Vergrößerung: 40fach. H: Ausschnitt des Zahnhalteapparates eines klinisch parodontal erkrankten Patienten; CD 29-positive Endothelzellen; Vergrößerung: 10 fach. 


\subsubsection{Immunhistochemischer Nachweis von CD 44}

Bei parodontal gesunden und erkrankten Patienten zeigten sich bis auf einzelne Ausnahmen prinzipiell CD 44-positive zementnahe Zellen (siehe Abbildung 15C und D), Fibroblasten (siehe Abbildung 15E und F) und Endothelzellen (siehe Abbildung 15G und H). Im Hinblick auf die Verteilung waren keine besonderen Auffälligkeiten festzustellen, jedoch schwankte die Anzahl angefärbter Zellen innerhalb der untersuchten Proben. Zudem wiesen parodontal erkrankte Probanden generell eine schwächere Färbung der Zellen auf (siehe Abbildungen 15A und B). Alle Proben hatten eine schwach positive Hintergrundfärbung.

Tabelle 14: Nachweis des Antikörpers CD 44; ,,+“= positiv; , $(+)^{“}=$ schwach positiv; ,,““ = negativ; ,,n. b. $.^{“}=$ nicht beurteilbar; EZM = extrazelluläre Matrix.

\begin{tabular}{cccccc}
\hline $\begin{array}{c}\text { klinischer } \\
\text { partodontaler Befund }\end{array}$ & Patient & $\begin{array}{c}\text { zementnahe } \\
\text { Zellen }\end{array}$ & Fibroblasten & Endothel & EZM \\
\hline krank & K1 & $(+)$ & $(+)$ & $(+)$ & $(+)$ \\
krank & K2 & $(+)$ & $(+)$ & $(+)$ & $(+)$ \\
krank & K3 & $(+)$ & $(+)$ & $(+)$ & + \\
gesund & G1 & $(+)$ & $(+)$ & + & $(+)$ \\
gesund & G2 & + & + & n.b. & $(+)$ \\
gesund & G3 & + & + & + & $(+)$ \\
\hline
\end{tabular}



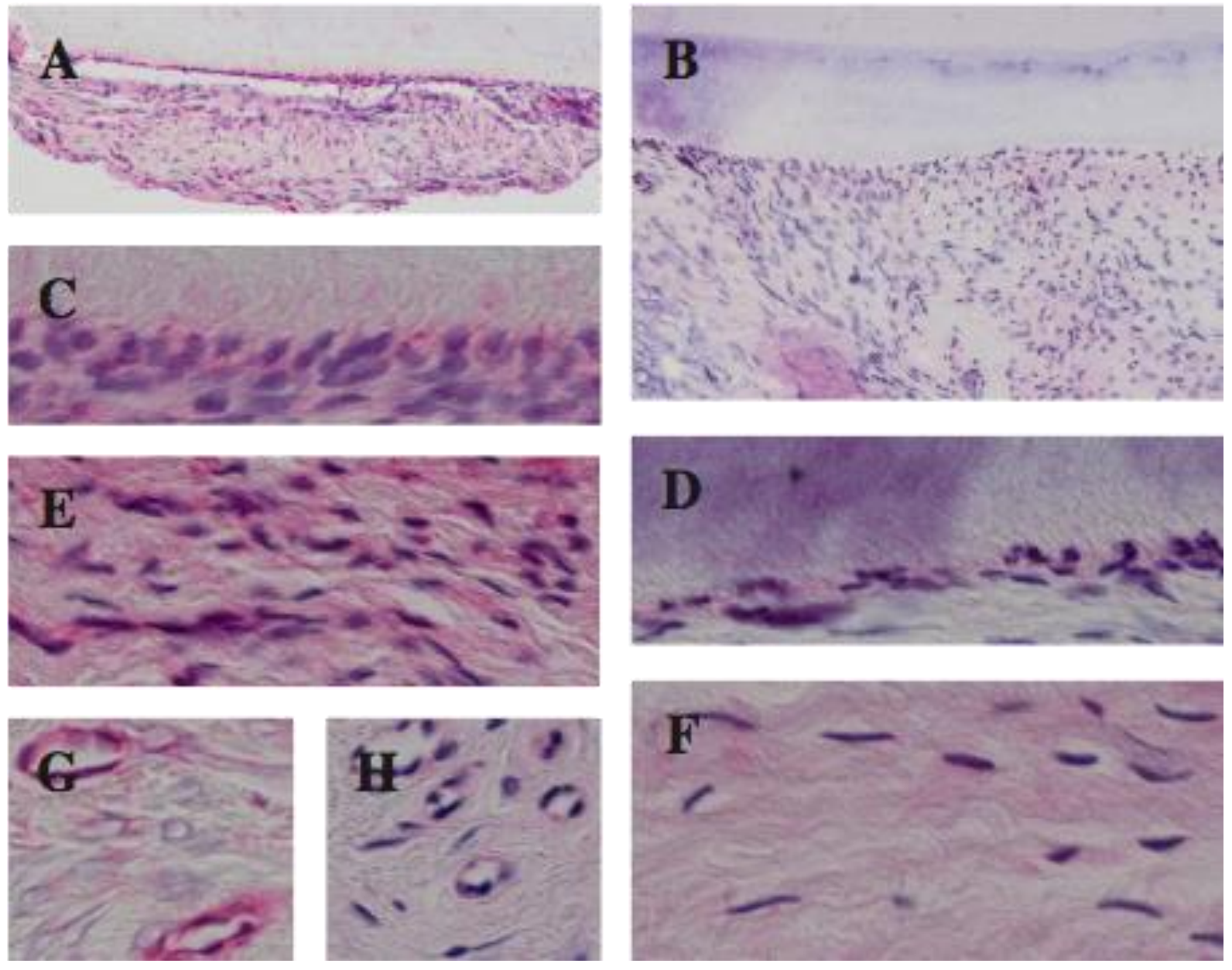

Abbildung 15: Immunhistochemische CD 44-Färbung. A: Ausschnitt des Zahnhalteapparates eines klinisch parodontal gesunden Patienten; Übersicht; Vergrößerung: 10fach. B: Ausschnitt des Zahnhalteapparates eines klinisch parodontal gesunden Patienten; Übersicht; Vergrößerung: 10fach. C: Ausschnitt des Zahnhalteapparates eines klinisch parodontal gesunden Patienten; CD 44-positive zementnahe Zellen; Vergrößerung: 40fach. D: Ausschnitt des Zahnhalteapparates eines klinisch parodontal erkrankten Patienten; schwach CD 44-positive zementnahe Zellen; Vergrößerung: 40fach. E: Ausschnitt des Zahnhalteapparates eines klinisch parodontal gesunden Patienten; CD 44-positive Fibroblasten; Vergrößerung: 40fach. F: Ausschnitt des Zahnhalteapparates eines klinisch parodontal erkrankten Patienten; schwach CD 44-positive Fibroblasten; Vergrößerung: 40fach. G: Ausschnitt des Zahnhalteapparates eines klinisch parodontal gesunden Patienten; CD 44-positive Endothelzellen; Vergrößerung: 40fach. H: Ausschnitt des Zahnhalteapparates eines klinisch parodontal erkrankten Patienten; schwach CD 44-positive Endothelzellen; Vergrößerung: 40fach. 


\subsubsection{Immunhistochemischer Nachweis von CD 90 (Thy-1)}

Innerhalb des untersuchten Probandenguts zeigten sich sowohl bei parodontal gesunden als auch bei parodontal erkrankten Patienten im PDL-Gewebe CD 90-positive zementnahe Zellen (siehe Abbildungen 16C und D), Fibroblasten (siehe Abbildungen 16C und F) und Endothelzellen (siehe Abbildungen 16E und G). Fulminante Unterschiede waren hinsichtlich des parodontalen Befundes nicht auszumachen (siehe Abbildungen 16A und B). Die Quantität angefärbter Zellen schwankte innerhalb der Stichproben, lag jedoch insgesamt auf einem relativ hohen Level. Alle Proben wiesen eine mehr oder weniger starke Hintergrundfärbung auf, die sich lediglich auf die dargestellten Weichgewebe beschränkte. Die Färbung des Endothels fiel am deutlichsten aus. Zudem waren bei parodontal erkrankten Patienten tendenziell mehr angefärbte Gefäße aufzufinden.

Tabelle 16: Nachweis des Antikörpers CD 90; ,,+“" = positiv; „, $(+)^{“}=$ schwach positiv; ,,““ = negativ; ,„n. b.“ nicht beurteilbar; EZM = extrazelluläre Matrix.

\begin{tabular}{|c|c|c|c|c|c|}
\hline $\begin{array}{c}\text { klinischer } \\
\text { partodontaler Befund }\end{array}$ & Patient & $\begin{array}{c}\text { zementnahe } \\
\text { Zellen }\end{array}$ & Fibroblasten & Endothel & $\overline{E Z M}$ \\
\hline krank & $\mathrm{K} 1$ & + & + & + & + \\
\hline krank & $\mathrm{K} 2$ & $(+)$ & + & + & $(+)$ \\
\hline krank & K3 & $(+)$ & + & + & + \\
\hline gesund & G1 & $(+)$ & + & + & + \\
\hline gesund & $\mathrm{G} 2$ & + & + & n.b. & + \\
\hline gesund & G3 & + & + & + & + \\
\hline
\end{tabular}



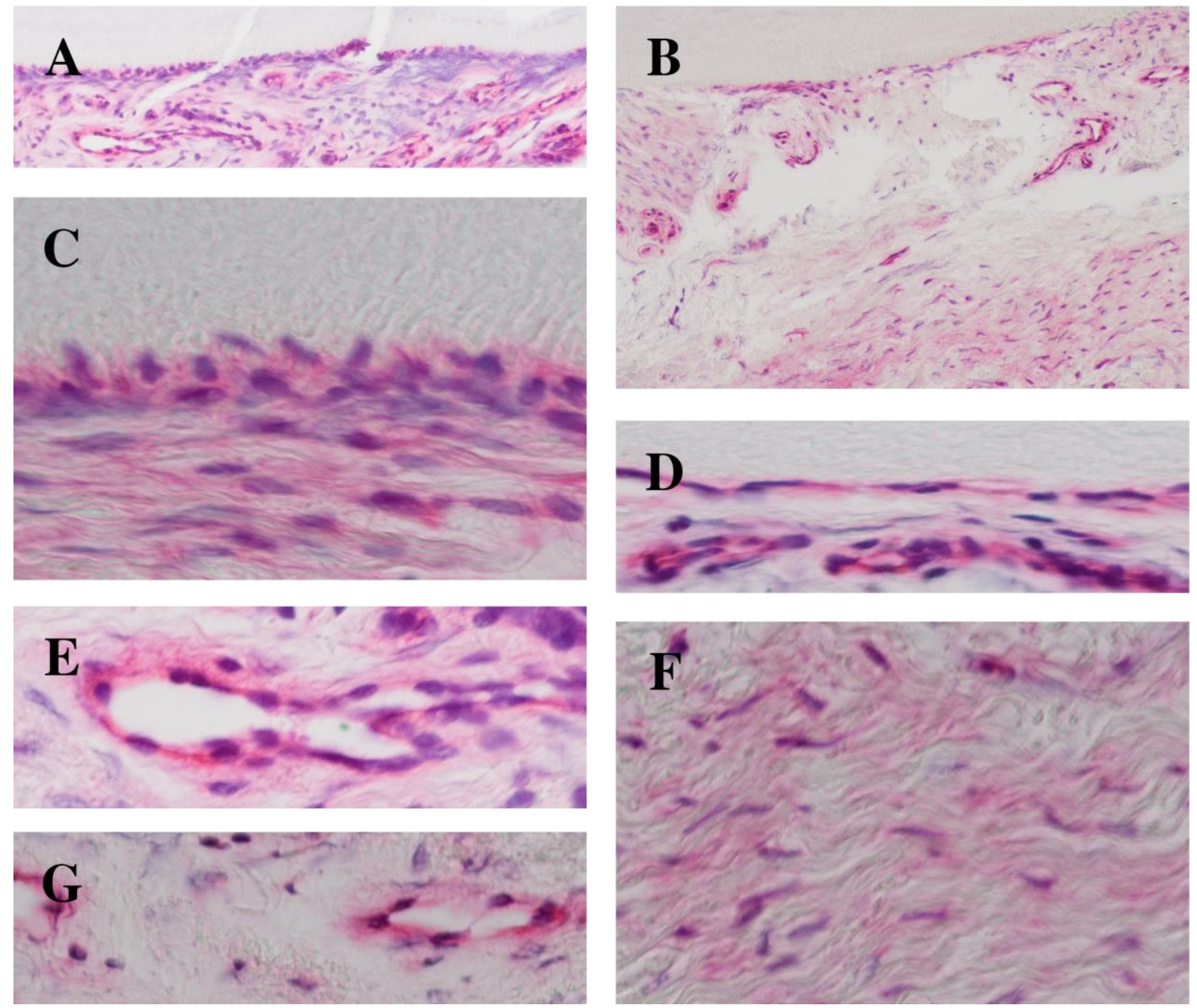

Abbildung 16: Immunhistochemische CD 90-Färbung. A: Ausschnitt des Zahnhalteapparates eines klinisch parodontal gesunden Patienten; Übersicht; Vergrößerung: 10fach. B: Ausschnitt des Zahnhalteapparates eines klinisch parodontal erkrankten Patienten; Übersicht; Vergrößerung: 10fach. C: Ausschnitt des Zahnhalteapparates eines klinisch parodontal gesunden Patienten; CD 90-positive zementnahe Zellen und Fibroblasten; Vergrößerung: 40fach. D: Ausschnitt des Zahnhalteapparates eines klinisch parodontal erkrankten Patienten; CD 90-positive zementnahe Zellen; Vergrößerung: 40fach. E: Ausschnitt des Zahnhalteapparates eines klinisch parodontal gesunden Patienten; CD 90-positive Endothelzellen; Vergrößerung: 40fach. F: Ausschnitt des Zahnhalteapparates eines klinisch parodontal erkrankten Patienten; CD 90-positive Fibroblasten; Vergrößerung: 40fach. G: Ausschnitt des Zahnhalteapparates eines klinisch parodontal erkrankten Patienten; CD 90-positive Endothelzellen; Vergrößerung: 40fach. 


\section{DISKUSSION}

\subsection{Diskussion der verwendeten Entzündungsmarker}

Verschiedene tierexperimentelle histologische Studien haben gezeigt, dass im Gewebe des klinisch gesunden Zahnhalteapparates Entzündungszellen wie Makrophagen, Granulozyten, Lymphozyten und Plasmazellen insbesondere in unmittelbarer Nähe zum gingivalen Sulkus ständig vorhanden sind (Adams et al. 1979, Adams et al. 1981, Avery und Simpson 1973). Beim Menschen konnte durch Biopsien gesunder Gingiva das Vorhandensein bestimmter Makrophagenpopulationen nachgewiesen werden (Topoll et al. 1989). Die Ergebnisse der vorliegenden Arbeit zeigen ein geringeres Vorkommen von Entzündungszellen im klinisch gesunden Zahnhalteapparat, beziehen sich jedoch auf das PDL-Gewebe. Dieses liegt anatomisch apikal des gingivalen Bindegewebes und ist somit weiter vom Saumepithel entfernt, welches zur ersten Abwehrreihe des Parodonts gehört (Schroeder und Listgarten 1997). Dieser Umstand könnte eine Erklärung für den geringeren und teilweise fehlenden Nachweis der Entzündungsmarker HAM-56, CD11 b und Anti-Neutrophil-Elastase im klinisch gesunden PDL liefern.

Zudem zeigt die vorliegende Arbeit prinzipiell ein vermehrtes Vorhandensein von Entzündungszellen im parodontal erkrankten PDL verglichen mit gesunden PDL. Anhand von Studien an Totenkopfäffchen und Hunden, bei denen durch das Einlegen von plaqueretentiven Ligaturen eine sogenannte experimentelle Parodontitis herbeigeführt wurde, konnte nachgewiesen werden, dass es zu einer Akkumulation von Entzündungszellen im gingivalen Bindegewebe kommt (Adams et al. 1979, Adams et al. 1981, Kennedy und Polson 1973, Schroeder und Lindhe 1975). Topoll et al. (1989) zeigten im Rahmen einer experimentellen Gingivitisstudie das vermehrte Vorkommen von bestimmten Makrophagenpopulationen durch Biopsien am Menschen. Die Forschergruppe um Gillett et al. (1986) wies ein erhöhtes Aufkommen inflammatorischer Zellen bei Menschen mit Parodontitis nach. Diese Arbeiten konzentrieren sich jedoch auf das gingivale Gewebe, welches nicht Gegenstand dieser Untersuchungen ist, mangels vergleichender histologischer Untersuchungen des PDL aber hier erwähnt werden sollen.

In Studien an Totenkopfäffchen setzte sich das supraalveoläre inflammatorische Zellinfiltrat primär aus Granulozyten und Makrophagen zusammen, wobei Lymphozyten und Plasma- 
zellen in deutlich geringerem Umfang vorhanden waren (Adams et al. 1979, Adams et al. 1981). Bei Untersuchungen am Menschen mit chronischer Parodontitis zeigten sich hingegen größere Variationen der Infiltratzusammensetzung, so dass entweder Lymphozyten oder Plasmazellen vermehrt vorhanden waren (Gillett et al. 1986). Das quantitative Aufkommen entzündlicher Zellpopulationen war jedoch in Studien bei parodontal erkrankten Probanden stets deutlich höher als bei gesunden (Avery und Simpson 1973). Die Ergebnisse der vorliegenden Arbeit erlauben zwar keine eindeutigen Rückschlüsse bezüglich des differentiellen Nachweises verschiedener Entzündungszellen, legen aber den Schluss nahe, dass die Menge an inflammatorischen Zellen im parodontal erkrankten PDL im Vergleich zum Infiltrat im gingivalen Bindegewebe reduziert ist. Zusätzlich $\mathrm{zu}$ bedenken ist, dass Granulationsgewebe extrahierter Zähne vor der histologischen Aufbereitung entfernt wurde, da dieses insbesondere in chronischen Stadien Entzündungszellen beherbergt. 


\subsection{Diskussion der histologischen Charakterisierung von Fibroblasten und zementnahen Zellen}

In der vorliegenden Arbeit stellte sich eine prinzipiell parallele Orientierung der Fibroblasten zum gewellt erscheinenden Faserverlauf dar. Diese Beobachtung stimmt mit früheren lichtund elektronenmikroskopischen Studien am menschlichen PDL überein (Becker et al. 1991, Raspanti et al. 2000).

Die meisten histologischen Studien zur Charakterisierung der Form von Fibroblasten stammen von Nagetieren. In diesen werden Fibroblasten als elongiert mit stark polarisiertem Zytoplasma jedoch auch als vielgestaltig beschrieben (Beertsen et al. 1979, Lekic et al. 1997, Roberts und Chamberlain 1978, Shore und Berkovitz 1979). Im menschlichen PDL wurden Fibroblasten als spindelförmig, eiförmig, deutlich elongiert und abgeflacht beschrieben (Berkovitz 1990, Bevelander und Nakahara 1968). Shore und Berkovitz (1979) fanden in einer ultrastrukturellen Studie des PDL-Gewebes von Ratten heraus, dass die Form der Fibroblastenzellkerne einer abgeflachten Scheibe ähnelt. Die vorliegenden Ergebnisse bestätigen diese Beobachtung für menschliches PDL-Gewebe, da sich Kerne, die in Längsrichtung angeschnitten wurden als länglich bis flach oval darstellten und entsprechend in Querrichtung als rundlich bis leicht oval.

Als Unterschied stellte sich eine tendenziell gesteigerte Zellzahl und Größe bei parodontal gesundem PDL-Gewebe heraus. Eine Erklärung hierfür könnte die Abnahme der Zellzahl mit steigendem Alter liefern, die bereits in zahlreichen tierexperimentellen Studien (Jensen und Toto 1968, Klingsberg und Butcher 1960, Toto et al. 1975) sowie beim Menschen (Grant und Bernick 1972) für das PDL beschrieben wurde. Dennoch liegt nach vorliegendem Kenntnisstand kein Artikel vor, der den klinischen parodontalen Befund in Abhängigkeit vom Alter differenziert. Neue Erkenntnisse könnten durch das Einbeziehen von jugendlichen Zähnen, die in Folge einer aggressiven Parodontitis extrahiert werden müssen, gewonnen werden. In der vorliegenden Arbeit stammt das in Abbildung 8 als klinisch krank dargestellte Präparat von einem Patienten der 30 Jahre älter ist als derjenige, dessen gesundes Vergleichspräparat abgebildet wurde.

Arbeiten zur histologischen Charakterisierung von Zementoblasten des Menschen stellen ihre Form als ungefähr oval dar (Bevelander und Nakahara 1968), wobei sie während der Wurzelentwicklung als große basophile Zellen variabler Gestalt die Osteoblasten ähneln beschrieben werden (Bosshardt und Schroeder 1990, Bosshardt und Schroeder 1991, 
Bosshardt und Schroeder 1992, Furseth 1974). Die durchgeführten Untersuchungen der vorliegenden Arbeit fanden jedoch stets an Zähnen mit abgeschlossenem Wurzelwachstum statt. Hierbei zeigte sich eine variable Formgebung der Kerne zementnaher Zellen unabhängig vom parodontalem Befund. Die Form der Zellen lässt sich anhand der vorliegenden Ergebnisse jedoch nicht beschreiben, da ihre Grenzen nicht erkennbar sind. Berkovitz und Shore (1982) stellten fest, dass die Erscheinung der Zementoblasten von ihrem Funktionsstatus abhängig ist. In den vorliegenden Resultaten waren die Kerne der zementnahen Zellenpopulationen, verglichen mit denen der Fibroblasten, stets kräftiger gefärbt. Somit liegt bei ihnen das lichtmikroskopische Äquivalent eines erhöhten Heterochromatinanteils vor, was für einen verminderten Metabolismus spricht. Eine Erklärung hierfür könnte die Tatsache liefern, dass die Hauptaufgabe der zementnahen Zellen nach Abschluss der Wachstumsphase darin besteht reparative Leistungen zu erbringen (Jones und Boyde 1972).

Wie bereits in der Einleitung erwähnt stellen die in der vorliegenden Arbeit als zementnah beschriebenen Zellen mutmaßliche undifferenzierte Stammzellen vom osteoblastischen Typ dar, repräsentieren also womöglich Zementoprogenitorzellen, aus denen aktive Zementoblasten hervorgehen können (Liu et al. 1997). 


\subsection{Diskussion des Nachweises von Kollagen I, III, IV und XII}

Zusammenfassend lässt sich festhalten, dass durch den immunhistochemischen Nachweis von Kollagen I, III, IV und XII im PDL-Gewebe keine Unterschiede zwischen klinisch parodontal gesunden und erkrankten Patienten auszumachen sind, obwohl Änderungen der Expressionslevel beschrieben worden sind.

Untersuchungen unserer Arbeitsgruppe hatten gezeigt, dass der mRNA-Level von Kollagen Typ I und IV im parodontal gesunden und erkrankten PDL des Menschen beim Microarray vergleichbar, jedoch bei der real time (RT)-PCR bei kranken Patienten erhöht war. Ferner fiel die Expression von Kollagen Typ III in der Microarray-Analyse bei kranken Patienten erniedrigt aus (Szydlik 2009). In der Arbeit von Stein (2011) unserer Arbeitsgruppe wurde hingegen eine Herunterregulation der Gene Kollagen Typ I alpha 1 und IV alpha 1 sowohl mithilfe der Microarray-Analyse als auch der real time (RT)-PCR bei parodontal erkrankten Patienten nachgewiesen.

Der mikroskopische Nachweis von Kollagen Typ I im Dentin, Zement und Desmodont wurde bereits in verschieden Tierspezies und beim Menschen erbracht und bestätigt die hier vorgelegten Ergebnisse (Becker et al. 1991, Butler et al.1975, Lukinmaa und Waltimo 1992, MacNeil et al. 1998).

In Studien an Ratten, Rindern und Krallenaffen wurde beschrieben, dass Kollagen Typ IFibrillen von Kollagenfibrillen des Typs III umschlossen werden (Romanos et al. 1992, Wang et al. 1980). Immunelektronenmikroskopische Studien des Menschen zeigten jedoch, dass Sharpey-Fasern nicht von Kollagen Typ III-Fibrillen umschlossen werden (Becker et al. 1991). Vielmehr ist Kollagen Typ III ein Hauptbestandteil der Fasern im PDL und offenbar gemeinsam mit Kollagen Typ I in Fibrillen vorhanden (Becker et al. 1991, Huang et al. 1991). Die hier gezeigten Ergebnisse untermauern diese Beobachtungen und zeigen eine schwache Färbung der EZM, die in allen Bereichen des Desmodonts vorhanden ist. Diese weist verglichen mit der Kollagen Typ I-Färbung ein ähnliches Verteilungsmuster im Desmodont auf.

Becker et al. (1991) berichteten zudem, dass Fasern im Zement spärlich, zementnahe Fibrillen schwach und zementferne Fibrillen stärker gefärbt erschienen. Diese Beobachtung kann immunhistochemisch unter Berücksichtigung der hier vorliegenden Ergebnisse zumindest 
nicht bestätigt werden. Ferner ist anhand der Resultate der vorliegenden Arbeit keine positive Färbung von Kollagen Typ III im Zement ersichtlich, wobei diese früheren Forschungsergebnissen folgend im fibrillären Anteil zu erwarten wäre. Die Evidenz hierfür basiert jedoch mit Ausnahme der Arbeitsgruppe um Becker et al. (1991), welche hingegen das Vorkommen von Prokollagen Typ III nachwies, überwiegend auf Tierexperimenten (Huang et al. 1991, Romanos et al. 1992, Takita et al. 1987, Wang et al. 1980). Antikörper gegen Prokollagen Typ III sollen bei gleicher Spezifität durch eine bessere Antigenität zu intensiveren Färbungen führen (Norwack et al. 1976, Fleischmajer et al. 1981). Ursächlich für das Fehlen von Kollagen Typ III-positiven Sharpey-Fasern im Zement könnte jedoch auch eine mangelnde Antigendemaskierung sein. Ein fehlender Anschnitt ist aufgrund der untersuchten Anzahl der Präparate nahezu auszuschließen .

Über ein geringes Vorkommen von Kollagen Typ III in Fasern des regulären, tubulären Dentins der Maus (Nagata et al. 1992) beziehungsweise Prokollagen Typ III im menschlichen Prädentin und Dentinkanälchen (Becker et al. 1986) wurde bereits berichtet. In zahlreichen anderen Studien, wie auch in der vorliegenden Arbeit, konnte dessen Anwesenheit hingegen nicht bestätigt werden (Huang et al. 1991, Romanos et al. 1992, Takita et al. 1987, Wang et al. 1980). Eine Erklärung für diese kontroversen Ergebnisse könnten die von der Arbeitsgruppe um Becker et al. (1986) speziell entwickelten Dekalzifizierungs- und Fixierungsmethoden liefern, bei denen ein Verlust der Antigenität verhindert werden soll. Zudem ist die bereits erwähnte bessere Antigenität von Prokollagen Typ III zu bedenken. Letztendlich ist der Anteil untersuchten Dentins in der vorliegenden Arbeit nur auf zementnahe Bereiche beschränkt und die Aussagekraft somit eingeschränkt.

Butler et al. (1975) und Wang et al. (1980) fanden heraus, dass die Wände einiger Blutgefäße im PDL von Schweinen und Rindern eine stark positive Kollagen Typ III-Färbung aufwiesen. Die Resultate der vorliegenden Arbeit deuten dieses Ergebnis auch für das menschliche PDL an. So konnten vereinzelt schwach positive Gefäßwände beobachtet werden (Ergebnisse nicht gezeigt). Gleichwohl sind die Ergebnisse der vorliegenden Arbeit für einen stichhaltigen Nachweis nicht ausreichend.

Der Nachweis von Kollagen Typ IV beschränkte sich in der vorliegenden Arbeit auf die Basalmembran angeschnittener Blutgefäße im PDL des Menschen, die wie bereits zuvor erwähnt reichlich vorhanden waren (Berkovitz 2004, Hassel 1993). Die Blutversorgung des PDLs wurde bereits in zahlreichen tierexperimentellen Studien untersucht (Bernick 1962, 
Birn 1966, Carranza et al. 1966, Matsuo und Takahashi 2002). In einer elektronenmikroskopischen Studie des gesunden menschlichen PDL wurde über dünnwandige Gefäße, die Kapillaren ähneln und deutlich unterschiedliche Durchmesser aufweisen, berichtet (Bevelander und Nakahara 1968). Diese Ergebnisse decken sich mit den hier vorliegenden lichtmikroskopischen Beobachtungen wobei berücksichtigt werden muss, dass aufgrund der Abwesenheit des Alveolarknochens nur eine eingeschränkte Aussage möglich ist.

Über das Vorkommen von Kollagen Typ XII im PDL des Rindes berichtete erstmals die Forschergruppe um Dublet et al. (1988). Ferner wurde gezeigt, dass seine Expression in der Maus und in der Ratte zeitlich mit der Organisation und Reifung des PDLs ansteigt (MacNeil et al. 1998, Karimbux et al. 1992). In einem Zahnbewegungsexperiment der Ratte konnte zudem nachgewiesen werden, dass es zu einem temporären Anstieg der Kollagen Typ XII mRNA während der Reorganisation im PDL kommt (Karimbux und Nishimura 1995). Hieraus wurde der Schluss gezogen, dass die Expression von Kollagen Typ XII mit der funktionellen Regeneration des PDL assoziiert ist. Im Rahmen des hier vorliegenden immunhistochemischen Nachweises von Kollagen Typ XII im gesunden und erkrankten PDL konnten jedoch keine Unterschiede festgestellt werden. Eine Genexpressionsanalyse könnte hier weitere Erkenntnisse liefern. Dennoch ist nach vorliegendem Kenntnisstand ein vergleichender immunhistochemischer Nachweis von Kollagen Typ XII im PDL des Menschen nicht bekannt. In der vorliegenden Arbeit war Typ XII-Kollagen gleichmäßig im Desmodont verteilt. Da es sich hierbei um ausgereiftes PDL handelt, bestätigen die Ergebnisse von Karimbux et al. (1992) das Resultat dieser Arbeit. Mittels in-situHybridisierung im reifen PDL der Ratte wurde eine deutliche Expression der entsprechenden mRNA aufgezeigt, die sich über das gesamte Desmodont erstreckt. In diesem Zusammenhang wird zwar auch über eine deutlichere Expression im Bereich des Knochens berichtet, jedoch fehlt dieser Anteil in der vorliegenden Arbeit.

Die in den meisten Präparaten beobachtete stärkere zementnahe Färbung der EZM steht aber im Widerspruch mit Karimbux et al. (1992). Ein Zusammenhang mit dort vermehrt stattfindenden Umbauprozessen ist denkbar.

Der immunhistochemische Nachweis von Kollagen Typ XII im Hartgewebe des Menschen konnte nicht erbracht werden. Über Gründe kann nur spekuliert werden, da es als Bestandteil der fibrillenassoziierten Kollagene (FACIT) auch in Kollagen Typ I-reichen Geweben wie 
Sehnen nachgewiesen wurde, hier jedoch auch nach Reifung vermindert expremiert wird (Zhang et al. 2003).

Ferner zeigten die Ergebnisse der vorliegenden Arbeit eine positive Färbung im Bereich von Blutgefäßen sowohl im gesunden als auch im erkrankten PDL auf. In der Literatur wurde bereits das Vorkommen von Kollagen Typ XII in Gefäßwänden embryonaler Gewebe des Huhns und der Maus beschrieben (Oh et al. 1993, Wälchli et al. 1994). Über das Vorhandensein im PDL wurde nach vorliegendem Kenntnisstand noch nicht berichtet. 


\subsection{Diskussion der Stammzellmarker/Adhäsionsmoleküle CD 29, CD 44 und CD 90}

Integrine sind heterodimere Zelladhäsionsmoleküle, die jeweils aus einer alpha- und einer beta-Untereinheit aufgebaut sind und entsprechend ihrer beta-Untereinheit eingeteilt werden (Hemler et al. 1987). CD 29, auch Integrin beta 1 genannt, ist als vielfach expremiertes Adhäsionsmolekül an Zell-Zell und Zell-Matrix-Interaktionen beteiligt (Albelda und Buck 1990) und auch im Zahnhalteapparat vorhanden. Histologisch konnte es bereits im gesunden PDL-Gewebe von Maus und Ratte auf Zementoblasten, Fibroblasten und Endothelzellen nachgewiesen werden (Matias et al. 2003, Steffensen et al. 1992). Die Ergebnisse der vorliegenden Arbeit bestätigen diese Resultate für das PDL des Menschen. Überdies untermauern in-vitro-Studien die Anwesenheit von CD 29 als mutmaßlichem Stammzellmarker im PDL des Menschen (Kim et al. 2012, Trubiani et al. 2005).

Ein histologischer Vergleich von CD 29 in gesundem und erkranktem Gewebe des menschlichen Parodonts wurde bislang nur für die Gingiva jedoch nicht für das PDL durchgeführt. Del Castillo et al. (1996) berichtete über ein breites Vorhandensein von beta-1 Integrinen auf Epithelzellen, Endothelzellen, Bindegewebszellen und Entzündungszellen, das im erkrankten Gewebe ansteigt. Hierbei konnte im Speziellen ein Anstieg von alpha-4 und alpha-6 positiven Zellen im parodontitischen Gewebe festgestellt werden, die möglicherweise überwiegend Entzündungszellen repräsentieren. Die Arbeitsgruppe um Haapasalmi et al. (1995) beobachtete eine variable Verteilung von Integrin beta 1 auf Zellen der chronisch erkrankten Gingiva des Menschen, wobei dies in entzündeten Bereichen auf einer Hochregulation und in Bereichen der Wundheilung auf einer Runterregulation der Genexpression beruhen soll. Da in dieser Arbeit jedoch weniger Entzündungszellen im PDL aufgefunden wurden, könnten hierdurch vergleichbare Mengen CD 29-positiver Zellen in parodontal gesunden und erkrankten Individuen erklärt werden.

CD 44 dient als Zelloberflächenrezeptor für Matrixbestandteile wie Hyaloronsäure, Kollagen und Fibronektin (Aruffo et al. 1990, Jalkanen und Jalkanen 1992, Wayner und Carter 1987) und wird auf einer Reihe von Zelltypen expremiert. Histologisch wies Häkkinen et al. (1993) das Vorkommen von CD 44 auf Epithel- und Bindegewebszellen der Gingiva sowie auf Zellen des PDL-Gewebes im menschlichen Zahnhalteapparat nach. Die Forschergruppe um Leonardi et al. (2006) bestätigten anhand von gesunden, aus kieferorthopädischen Gründen extrahierten, 
Zähnen das Vorkommen von CD 44-positiven Zellen im PDL und beschrieb erstmals schwach positive Zementoblasten. Ferner konnten in-vitro-Untersuchungen von gesunden menschlichen Zellen der Gingiva und des PDL mittels Durchflusszytometrie zeigen, dass eine hohe Expression von CD 44 auf mutmaßlichen Stammzellen vorliegt (Hung et al. 2012, Kim et al. 2012, Trubiani et al. 2005). Die Ergebnisse der vorliegenden Arbeit decken sich mit den zuvor erwähnten Beobachtungen, liefern jedoch zusätzlich den immunhisto-chemischen Nachweis von CD 44 auf Endothelzellen.

Hirano et al. (1997) stellte in einer Studie zur zellspezifischen Expression von CD 44Isoformen unterschiedlicher parodontaler Gewebe des Menschen fest, dass der mRNA-Level in PDL-Zellen unter dem Einfluss proinflammatorischer Zytokine anstieg. Park et al. (2011) beobachtete hingegen, dass mutmaßliche menschliche Stammzellen von gesundem und erkranktem PDL in der Zellkultur einen ähnlichen mRNA-Level aufweisen. Zu bedenken ist jedoch, dass mit steigender Passagezahl parodontal erkranktes Gewebe sich in seinen Eigenschaften gesundem Gewebe angleicht (Entorf 2010). In einer immunhistochemischen Untersuchung, zur Lokalisierung mutmaßlicher Stammzellen im PDL des Menschen, zeigte sich bei gesunden und erkrankten Proben ein vergleichbares unspezifisches Verteilungs-muster CD 44-positiver Zellen in para- und extravaskulären Region (Chen et al. 2006). In den Ergebnissen der vorliegenden Arbeit waren ebenfalls Anzahl und Verteilung angefärbter Zellpopulationen bei gesunden und erkrankten Patienten stets vergleichbar.

Jedoch deuten diese Resultate gegensätzlich zu Hirano et al. (1997) darauf hin, dass im erkrankten PDL der Gehalt von CD 44 geringer ist. Ein quantitativer Proteinnachweis könnte hier zur Klärung beitragen. Oksala et al. (1997) fanden heraus, dass CD 44 im Gingivaepithel chronisch entzündeter Parodontien mikroskopisch fast nicht mehr nachweisbar war. Jedoch stieg dafür die Anzahl von CD 44-positiven Zellen im inflammatorischen Infiltrat des gingivalen Bindegewebes an. Eine Erklärung hierfür liefert die Fähigkeit von Lymphozyten, vermittelt durch CD 44, an Moleküle der EZM und an Gingivafibroblasten zu binden (Jalkanen und Jalkanen 1992, Murakami et al. 1996). Die bereits beschriebene verringerte Anwesenheit von Entzündungszellen im erkrankten PDL könnte also zusätzlich als Erklärung dienen. Eine gleichzeitig stattfindende Degradierung der EZM ist ebenfalls denkbar.

Bei Chen et al. (2006) war überdies CD 44 nur in 6 von 19 gesunden $(31,6 \%)$ beziehungsweise in 9 von 17 parodontal erkrankten $(52,5 \%)$ Zähnen überhaupt nachweisbar. In den Ergebnissen der vorliegenden Arbeit schwankte die Anzahl angefärbter Zellpopulationen 
innerhalb der untersuchten Proben zwar sowohl bei gesunden und erkrankten Patienten, dennoch war CD 44 immer nachweisbar.

Die in den hier vorliegenden Resultaten vorhandene prinzipielle Hintergrundfärbung wurde von Chen et al. (2006) auch beobachtet, war jedoch gegensätzlich zu den Ergebnissen der vorliegenden Arbeit bei erkrankten Patienten stärker ausgeprägt.

CD 90 ist ein Transmembranprotein, das beim Menschen in geringen Mengen im Gehirn (McKenzie und Fabre 1981 b), in lymphatischen Organen (McKenzie und Fabre 1981 a), auf hämatopoetischen Progenitorzellen (Craig et al. 1993), auf Fibroblasten (Saalbach et al. 1996, Saalbach et al. 1998) und aktivierten Endothelzellen (Saalbach et al. 1999) vorhanden ist. Obwohl die genaue Funktion noch nicht geklärt ist, scheint CD 90 in Zell-Zell und ZellMatrix-Interaktionen involviert zu sein (Rege et al. 2006).

Durch zahlreiche in-vitro-Untersuchungen der menschlichen Gingiva und des PDL konnte mittels Durchflusszytometrie gezeigt werden, dass in parodontal gesundem und erkranktem Gewebe eine hohe Expression von CD 90 auf mutmaßlichen Stammzellen vorliegt (Hung et al. 2012, Park et al. 2011, Tomokiyo et al. 2012, Trubiani et al. 2005, Wada et al. 2009). Zu bedenken ist aber dass, wie bereits erwähnt, erkrankte Zellen mit zunehmender Passagezahl sich in ihren Eigenschaften gesunden Zellen angleichen (Entorf 2010). Diese Ergebnisse decken sich mit dem in der vorliegenden Arbeit, unabhängig vom parodontalen Befund, vorgefundenen vergleichbaren Vorkommen von CD 90-positiven Zellen. Dennoch ist nach vorliegendem Kenntnisstand bislang in keiner histologischen Arbeit CD 90 im PDL des Menschen vergleichend untersucht worden.

Die vorliegende Arbeit zeigt somit vermutlich erstmals histologisch CD 90-positive Zementoblasten, Fibroblasten und Endothelzellen im parodontal gesunden und erkrankten PDL des Menschen. Die Arbeitsgruppe um Saalbach et al. (1996) berichtete über einen Anstieg der Expression von Thy-1 auf menschlichen Fibroblasten während frühen Phasen der Wundheilung und zog den Schluss, dass CD 90 durch inflammatorische Mediatoren aktiviert wird.

In einer weiteren Studie beobachtete Saalbach et al. (2000), dass PMN und Monozyten über einen möglichen Thy-1-Liganden an aktivierte Endothelzellen und Fibrolasten der menschlichen Haut binden können. Somit würde für parodontal entzündetes Gewebe ein höheres Vorkommen an CD 90 erwartet werden. Ein vergleichbares Vorkommen in der 
Diskussion

vorliegenden Arbeit könnte jedoch durch die relativ geringe Anwesenheit von Entzündungszellen begründet sein. Das tendenziell leicht vermehrte Vorliegen von CD 90positivem Endothel bei parodontal erkrankten Patienten hingegen spricht für eine vermehrte Aktivierung, die möglicherweise durch TNF-alpha bedingt ist. Diese Aktivierung konnte durch Saalbach et al. (1999) in vitro und in situ am Menschen gezeigt werden.

Abschließend ist festzuhalten, dass entgegengesetzt $\mathrm{zu}$ Chen et al. (2006) alle in der vorliegenden Arbeit genutzten mesenchymalen Stammzellmarker in jedem untersuchten Zahn nachweisbar waren. Dabei muss darauf hingewiesen werden, dass mit Ausnahme von CD 44 andere Marker Verwendung fanden. Diese Ergebnisse stehen im Einklang mit zahlreichen im Rahmen der Durchflusszytometrie beobachteten hohen Expressionsraten auf mutmaßlichen Stammzellpopulationen (Kim et al. 2012, Tomokiyo et al. 2012, Trubiani et al. 2005, Wada et al. 2009). Letztendlich konnte - abgesehen von CD 90 - mit der vorliegenden Arbeit ein vermehrtes Vorkommen von CD 29 und CD 44 bei parodontal erkrankten Patienten nicht nachgewiesen werden. Möglicherweise könnten hier histologische Untersuchungen an Proben aus der Pathologie, die den angrenzenden Alveolarknochen mit beinhalten für Aufklärung sorgen, da vermutet wird, dass sich in diesem Bereich eine Stammzellnische befindet (McCulloch et al. 1987). Ferner ist zu bedenken, dass CD 29, 44 und 90 zwar in die Isolierung mesenchymaler Stammzellen involviert sind, diese jedoch als Adhäsionsmoleküle auf einer Vielzahl von Zelltypen anzutreffen sind (Kemp et al. 2005). Ein spezifischer Marker mesenchymaler Stammzellen ist nach vorliegendem Kenntnisstand noch nicht bekannt. 


\section{ZUSAMMENFASSUNG}

Entzündliche Erkrankungen des Zahnhalteapparates (Parodontitiden) sind durch einen irreversiblen Verlust von Gewebe, das der Verankerung des Zahns dient, gekennzeichnet und haben in Deutschland die Karies als Hauptursache für den Zahnverlust abgelöst.

Das Hauptaugenmerk der vorliegenden Arbeit ist auf das parodontale Ligamentgewebe (PDL) gerichtet, welches letztendlich die Verbindung des Zahns zum Kieferknochen ermöglicht. Neben Gingiva, Zahnzement und PDL umfasst der Zahnhalteapparat als funktionelle Einheit auch Alveolarknochen, so dass seine Erforschung aus ethischen Gründen am Menschen erschwert ist und folglich ein Großteil der bereits gewonnen Evidenz auf Tierversuchen fußt. Gleichwohl existieren einige wichtige histologische Studien über das menschliche PDL, wobei insbesondere zelluläre und strukturelle Bestandteile auch im Hinblick auf Stammzellen sowie wichtige Bestandteile der extrazellulären Matrix untersucht wurden. Dennoch sind viele Fragestellungen in Bezug auf das PDL des Menschen noch nicht ausreichend beantwortet. Eine systematisch vergleichende histologische Untersuchung des gesunden und parodontitisch erkrankten menschlichen PDL existiert nach gegenwärtigem Kenntnisstand nicht und soll im Rahmen dieser Arbeit unternommen werden.

In der vorliegenden Arbeit konnte durch die Verwendung der Entzündungsmarker HAM-56, CD $11 \mathrm{~b}$ und Anti-Neutrophil-Elastase gezeigt werden, dass im parodontal erkrankten PDL zwar prinzipiell mehr Entzündungszellen vorhanden sind, deren Anzahl jedoch insgesamt relativ gering ist. Bei der Charakterisierung von Fibroblasten und zementnahen Zellen stellte sich eine gesteigerte Zellzahl und Größe im gesunden Desmodont dar, die jedoch vermutlich besser durch Alterungsprozesse als durch Parodontitis erklärt werden kann. Im Zuge des immunhistochemischen Nachweises der Kollagene vom Typ I, III, IV und XII waren zwischen gesunden und erkrankten Proben keine Unterschiede auszumachen. Nichtsdestoweniger konnte konträr zu früheren Beobachtungen Kollagen Typ III im Wurzelzement nicht nachgewiesen werden. Nach vorliegendem Kenntnisstand wurde zudem der lichtmikroskopische Nachweis von Kollagen Typ XII im menschlichen PDL zum ersten mal erbracht. Diesbezüglich war im Weichgewebe eine gleichmäßige Färbung des Faserapparates sowie eine Färbung von Blutgefäßen zu beobachten. Hartgewebe blieben hingegen ungefärbt. Im Rahmen der Untersuchung hinsichtlich mesenchymaler Stammzellmarker wurden abgesehen vom 
tendenziell vermehrten Vorkommen CD 90-positiver Endothelzellen im erkranktem PDL keine Unterschiede im Hinblick auf den parodontalen Zustand ersichtlich. Dennoch konnten durch die vorliegende Arbeit nach gegenwärtigem Kenntnisstand erstmals CD 29- und CD 90positive Fibroblasten und zementnahe Zellen sowie CD 29-, 44- und 90-positive Endothelzellen histologisch im gesunden und erkrankten PDL nachgewiesen werden. 


\section{ANHANG}

\subsection{Abbildungsverzeichnis}

Abbildung Abbildungstitel

Seite

Abbildung 1 Aufbau des Zahnhalteapparates. Entnommen aus: Rateitschak KH, Rateitschak M, Wolf HF: Parodontologie; in: Farbatlanten der Parodontologie; Rateitschak KH, Band I; Georg Thieme Verlag, Stuttgart - New York 1989

Abbildung 2 Pathogenese der Parodontitis. Entnommen aus: Page RC, Kornman 10 KS (1997): The pathogenesis of human periodontitis: an introduction. Periodontol $2000 \underline{14}, 9-11$

Abbildung 3 Übersicht des menschlichen Zahnhalteapparates

Abbildung 4 Ausschnitt aus Abbildung 3; Schematische Darstellung des dem Zement zugewandten Teils des Zahnhalteapparates der untersuchten Proben

Abbildung 5 Immunhistochemische HAM-56-Färbung 26

Abbildung $6 \quad$ Immunhistochemische CD 11b-Färbung 27

Abbildung $7 \quad$ Immunhistochemische Anti-Neutrophil-Elastase-Färbung 28

$\begin{array}{llr}\text { Abbildung } 8 & \text { Charakterisierung von Fibroblastenzellkernen } & 29\end{array}$

Abbildung 9 Charakterisierung von Zellkernen zementnaher Zellen 30

Abbildung 10 Immunhistochemische Kollagen Typ I-Färbung 31

Abbildung 11 Immunhistochemische Kollagen Typ III-Färbung 32

Abbildung 12 Immunhistochemische Kollagen Typ IV-Färbung 33

Abbildung 13 Immunhistochemische Kollagen Typ XII-Färbung 34

Abbildung 14 Immunhistochemische CD 29-Färbung 36

Abbildung 15 Immunhistochemische CD 44-Färbung 38

Abbildung $16 \quad$ Immunhistochemische CD 90-Färbung 40 


\subsection{Tabellenverzeichnis}

Seite

Tabelle $1 \quad$ Protokoll der Gewebedehydrierung und Überführung in Paraffin

Tabelle 2 Protokoll der Gewebeentparaffinierung und Rehydrierung

Tabelle 3 Protokoll für die Verwendung des Dako REAL ${ }^{\text {TM }}$ Detection Sytem

Alkaline Phosphatase/RED Rabbit/Mouse

Tabelle 4 Liste der verwendeten Antikörper mit Inkubationsbedingungen

Tabelle 5

Protokoll der Dehydrierung

Tabelle 6

Protokoll für die H.E.-Färbung mit dem Färbeautomat Stainix

Tabelle $7 \quad$ Nachweis des Antikörpers HAM-56 25

$\begin{array}{lll}\text { Tabelle } 8 & \text { Nachweis des Antikörpers CD 11b } & 27\end{array}$

Tabelle $9 \quad$ Nachweis des Antikörpers Anti-Neutrophil-Elastase 28

Tabelle $10 \quad$ Nachweis des Antikörpers Kollagen Typ I 31

Tabelle $11 \quad$ Nachweis des Antikörpers Kollagen Typ III 32

Tabelle $12 \quad$ Nachweis des Antikörpers Kollagen Typ XII 34

Tabelle $13 \quad$ Nachweis des Antikörpers CD 29 35

$\begin{array}{lll}\text { Tabelle } 14 & \text { Nachweis des Antikörpers CD } 44\end{array}$

Tabelle $15 \quad$ Nachweis des Antikörpers CD 90 


\subsection{Abkürzungsverzeichnis}

$\begin{array}{ll}\text { Abkürzung } & \text { Erklärung } \\ { }^{\circ} & \text { Grad } \\ { }^{\circ} \mathrm{C} & \text { Grad Celsius } \\ \% & \text { Prozent } \\ \mu \mathrm{m} & \text { Mikrometer } \\ \mathrm{AK} & \text { Antikörper }\end{array}$

Aqua dest. Aqua destillata

BSA bovine serum albumin

CAP cementum attachment-Protein

CD cluster of differentiation

EDTA ethylendiamintetraacetic acid

ER endoplasmatisches Retikulum

EZM extrazelluläre Matrix

FACIT fibril associated collagens with interrupted triple helices

g Gramm

H.E. Hämatoxylin-Eosin

LSAB labelled streptavidin-biotin

M Molarität

Mac-1 macrophage-1 antigen

ml Milliliter

mm Millimeter

mRNA messenger ribonucleic acid

N Normalität

PBS phosphate buffered saline

PDL parodontales Ligament

$\mathrm{pH} \quad$ negativ dekadischer Logarithmus der Oxoniumionenkonzentration

PMN polymorphonuclear neutrophils 
RT

Raumtemperatur

(RT)-PCR

reverse transcription polymerase chain reaction

Thy-1

thymocyte differentiation antigen 1

TNF-alpha Tumor-Nekrose-Faktor-alpha

z.B.

zum Beispiel 


\section{LITERATURVERZEICHNIS}

Adams RA, Zander HA, Polson AM (1979): Cell populations in the transseptal fiber region before, during and after experimental periodontitis in squirrel monkeys. J Periodontol 50(1), 712

Adams RA, Zander HA, Polson AM (1981): Interproximal and buccal cell populations apical to the sulcus before and during experimental periodontitis in squirrel monkeys. J Periodontol $\underline{52}(8), 416-9$

Ainamo J, Löe H (1966): Anatomical characteristics of gingiva. A clinical and microscopic study of the free and attached gingiva. J Periodontol $\underline{37(1), 5-13}$

Albelda SM, Buck CA (1990): Integrins and other cell adhesion molecules. FASEB J $\underline{4}(11)$, $2868-80$

Aruffo A, Stamenkovic I, Melnick M, Underhill CB, Seed B (1990): CD44 is the principal cell surface receptor for hyaluronate. Cell $\underline{61}(7), 1303-13$

Avery BE, Simpson DM (1973): The baboon as a model system for the study of periodontal disease: clinical and light microscopic observations. J Periodontol 444(11), 675-86

Barden A, Graham D, Beilin LJ, Ritchie J, Baker R, Walters BN, Michael CA (1997): Neutrophil CD11B expression and neutrophil activation in pre-eclampsia. Clin Sci (Lond) $\underline{92}(1), 37-44$

Bartold PM, Narayanan AS (2006): Molecular and cell biology of healthy and diseased periodontal tissues. Periodontol $2000 \underline{40}, 29-49$

Bartold PM, Walsh LJ, Narayanan AS (2000): Molecular and cell biology of the gingiva. Periodontol $2000 \underline{24}, 28-55$

Becker J, Schuppan D, Benzian H, Bals T, Hahn EG, Cantaluppi C, Reichart P (1986): Immunohistochemical distribution of collagens types IV, V, and VI and of pro-collagens types I and III in human alveolar bone and dentine. J Histochem Cytochem 34(11), 1417-29

Becker J, Schuppan D, Rabanus JP, Rauch R, Niechoy U, Gelderblom HR (1991): Immunoelectron microscopic localization of collagens type I, V, VI and of procollagen type III in human periodontal ligament and cementum. J Histochem Cytochem 39(1), 103-10 
Becktor KB, Nolting D, Becktor JP, Kjaer I (2007): Immunohistochemical localization of epithelial rests of Malassez in human periodontal membrane. Eur J Orthod 29(4), 350-3

Beertsen W, Everts V, Brekelmans M (1979): Unipolarity of fibroblasts in rodent periodontal ligament. Anat Rec 195(3), 535-44

Bergström J (1984): The topography of papillary gingiva in health and early gingivitis. J Clin Periodontol 11(7), 423-31

Berkovitz BKB (1990): The structure of the periodontal ligament: an update. Eur J Orthod $\underline{12}(1), 51-76$

Berkovitz BKB (2004): Periodontal ligament: structural and clinical correlates. Dent Update $\underline{31}(1), 46-50,52,54$

Berkovitz BKB, Shore RC: Cells of the periodontal ligament; in: The periodontal ligament in health and disease; Berkovitz BKB, Moxham HN, Newman HN; Pergamon Press, Oxford 1982, $25-50$

Bernick S (1962): Age changes in the blood supply to molar teeth of rats. Anat Rec $\underline{144}, 265-$ 74

Bevelander G, Nakahara H (1968): The fine structure of the human peridental ligament. Anat Rec 162(3), 313-25

Bien SM (1966): Fluid dynamic mechanisms which regulate tooth movement. Adv Oral Biol $\underline{2}, 173-201$

Birkedal-Hansen H (1993): Role of cytokines and inflammatory mediators in tissue destruction. J Periodontal $\underline{28}(6$ Pt 2), 500-10

Birkedal-Hansen H, Butler WT, Taylor RE (1977): Proteins of the periodontium. Characterization of the insoluble collagens of bovine dental cementum. Calcif Tissue Res $\underline{23}(1), 39-44$

Birn H (1966): The vascular supply of the periodontal membrane. An investigation of the number and size of perforations in the alveolar wall. J Periodontal Res $\underline{1}, 51-68$

Bosshardt DD, Schroeder HE (1990): Evidence for rapid multipolar and slow unipolar production of human cellular and acellular cementum matrix with intrinsic fibers. J Clin Periodontol 17(9), 663-8 
Bosshardt DD, Schroeder HE (1991): Initiation of acellular extrinsic fiber cementum on human teeth. A light- and electron-microscopic study. Cell Tissue Res 263(2), 311-24

Bosshardt DD, Schroeder HE (1992): Initial formation of cellular intrinsic fiber cementum in developing human teeth. A light- and electron-microscopic study. Cell Tissue Res 267(2), 32135

Bosshardt DD, Selvig KA (1997): Dental cementum: the dynamic tissue covering of the root. Periodontol $2000 \underline{13}, 41-75$

Bosshardt DD, Lang NP (2005): The junctional epithelium: from health to disease. J Dent Res $\underline{84}(1), 9-20$

Butler WT, Birkedal-Hansen H, Beegle WF, Taylor RE, Chung E (1975): Proteins of the periodontium. Identification of collagens with the [alpha1(I)]2alpha2 and [alpha1(III)]3 structures in bovine periodontal ligament. J Biol Chem 250(23), 8907-12

Carbonell WS, DeLay M, Jahangiri A, Park CC, Aghi MK (2013): $\beta 1$ integrin targeting potentiates antiangiogenic therapy and inhibits the growth of bevacizumab-resistant glioblastoma. Cancer Res $\underline{73}(10), 3145-54$

Carranza FA Jr, Itoiz ME, Cabrini RL, Dotto CA (1966): A study of periodontal vascularization in different laboratory animals. J Periodontal Res $\underline{1}(2), 120-8$

Carter DH, Sloan P (1994): The fibrous architecture of the rat periodontal ligament in cryosections examined by scanning electron microscopy. Arch Oral Biol $\underline{39}(11), 949-53$

Chávarry NG, Vettore MV, Sansone C, Sheiham A (2009): The relationship between diabetes mellitus and destructive periodontal disease: a meta-analysis. Oral Health Prev Dent $\underline{7}(2), 107-27$

Chen SC, Marino V, Gronthos S, Bartold PM (2006): Location of putative stem cells in human periodontal ligament. J Periodontal Res $\underline{41}(6), 547-53$

Cho MI, Garant PR (2000): Development and general structure of the periodontium. Periodontol $2000 \underline{24}$, 9-27

Consensus report (1996): o. Verf.; Consensus report. Periodontal diseases: pathogenesis and microbial factors. Ann Periodontol 1(1), 926-32

Craig W, Kay R, Cutler RL, Lansdorp PM (1993): Expression of Thy-1 on human hematopoietic progenitor cells. J Exp Med 177(5), 1331-42 
Darveau RP, Tanner A, Page RC (1997): The microbial challenge in periodontitis. Periodontol $2000 \underline{14}, 12-32$

Del Castillo LF, Schlegel Gómez R, Pelka M, Hornstein OP, Johannessen AC, von den Driesch P (1996): Immunohistochemical localization of very late activation integrins in healthy and diseased human gingiva. J Periodontal Res $\underline{31}(1), 36-42$

Demetriou NA, Ramfjord SP (1972): Premitotic labeling and inflammation in the gingiva of Rhesus monkeys. J Periodontol $\underline{43}(10), 606-13$

Deutsche Mundgesundheitsstudie: o. Verf.; Vierte Deutsche Mundgesundheitsstudie (DMS IV); Institut der deutschen Zahnärzte; im Auftrag der Bundeszahnärztekammer und kassenärztlicher Bundesvereinigung; Druckhaus Boeken, Leverkusen 2006

Duan Y, Fisher E, Malamud D, Golub E, Demuth DR (1994): Calcium-binding properties of SSP-5, the Streptococcus gordonii M5 receptor for salivary agglutinin. Infect Immun $\underline{62}(12), 5220-6$

Dublet B, Dixon E, de Miguel E, van der Rest M (1988): Bovine type XII collagen: amino acid sequence of a $10 \mathrm{kDa}$ pepsin fragment from periodontal ligament reveals a high degree of homology with the chicken alpha 1(XII) sequence. FEBS Lett 233(1), 177-80

Entorf AM: Etablierung einer Zellkultur von PDL-Fibroblasten aus parodontal erkranktem Zahnhalteapparat des Menschen. Med. Diss. Göttingen 2010

Fleischmajer R, Timpl R, Tuderman L, Raisher L, Wiestner M, Perlish JS, Graves PN (1981): Ultrastructural identification of extension aminopropeptides of type I and III collagens in human skin. Proc Natl Acad Sci U S A $\underline{78}(12), 7360-4$

Fullmer HM, Lillie RD (1958): The oxytalan fiber: a previously undescribed connective tissue fiber. J Histochem Cytochem $\underline{6}(6), 425-30$

Furseth R (1974): The fine structure of acellular cementum in young human premolars. Scand J Dent Res $\underline{82}(6), 437-41$

Gay IC, Chen S, MacDougall M (2007): Isolation and characterization of multipotent human periodontal ligament stem cells. Orthod Craniofac Res 10(3), 149-60

Genco RJ (1992): Host responses in periodontal diseases: current concepts. J Periodontol $\underline{63}(4$ Suppl), 338-55 
Gillett R, Cruchley A, Johnson NW (1986): The nature of the inflammatory infiltrates in childhood gingivitis, juvenile periodontitis and adult periodontitis: immunocytochemical studies using a monoclonal antibody to HLADr. J Clin Periodontol 13(4), 281-8

Gould TR, Melcher AH, Brunette DM (1977): Location of progenitor cells in periodontal ligament of mouse molar stimulated by wounding. Anat Rec 188(2), 133-41

Gown AM, Tsukada T, Ross R (1986): Human atherosclerosis. II. Immunocytochemical analysis of the cellular composition of human atherosclerotic lesions. Am J Pathol 125(1), 191207

Grant D, Bernick S (1972): The periodontium of ageing humans. J Periodontol 43⑾, 660-7 Groeneveld MC, Everts V, Beertsen W (1995): Alkaline phosphatase activity in the periodontal ligament and gingiva of the rat molar: its relation to cementum formation. J Dent Res $\underline{74}(7), 1374-81$

Groeneveld MC, Van den Bos T, Everts V, Beertsen W (1996): Cell-bound and extracellular matrix-associated alkaline phosphatase activity in rat periodontal ligament. Experimental oral biology group. J Periodontal Res $\underline{31}(1), 73-9$

\section{Haapasalmi K, Mäkelä M, Oksala O, Heino J, Yamada KM, Uitto VJ, Larjava H (1995):} Expression of epithelial adhesion proteins and integrins in chronic inflammation. Am J Pathol 147(1), 193-206

Häkkinen L, Oksala O, Salo T, Rahemtulla F, Larjava H (1993): Immunohistochemical localization of proteoglycans in human periodontium. J Histochem Cytochem 41(11), 1689-99

Hannig M, Joiner A (2006): The structure, function and properties of the acquired pellicle. Monogr Oral Sci 19, 29-64

Hassel TM (1993): Tissues and cells of the periodontium. Periodontol $2000 \underline{3}$, 9-38

Hemler ME, Huang C, Schwarz L (1987): The VLA protein family. Characterization of five distinct cell surface heterodimers each with a common 130,000 molecular weight beta subunit. J Biol Chem 262(7), 3300-9

Hirano F, Hirano H, Hino E, Takayama S, Saito K, Kusumoto Y, Shimabukuro Y, Murakami S, Okada H (1997): CD44 isoform expression in periodontal tissues: cell-type specific regulation of alternative splicing. J Periodontal Res $\underline{32}(8), 634-45$ 
Huang YH, Ohsaki Y, Kurisu K (1991): Distribution of type I and type III collagen in the developing periodontal ligament of mice. Matrix 11(1), 25-35

Hung TY, Lin HC, Chan YJ, Yuan K (2012): Isolating stromal stem cells from periodontal granulation tissues. Clin Oral Investig 16(4), 1171-80

Jalkanen S, Jalkanen M (1992): Lymphocyte CD44 binds the COOH-terminal heparinbinding domain of fibronectin. J Cell Biol $\underline{116}(3), 817-25$

Jensen JL, Toto PD (1968): Radioactive labeling index of the periodontal ligament in aging rats. J Dent Res $\underline{47}(1), 149-53$

Jonas IE, Riede UN (1980): Reaction of oxytalan fibers in human periodontium to mechanical stress. A combined histochemical and morphometric analysis. J Histochem Cytochem 28(3), $211-6$

Jones SJ, Boyde A (1972): A study of human root cementum surfaces as prepared for and examined in the scanning electron microscope. Z Zellforsch Mikrosk Anat 130(3), 318-37

Juhl M, Stoltze K, Reibel J (1988): Distribution of Langerhans cells in clinically healthy human gingival epithelium with special emphasis on junctional epithelium. Scand J Dent Res 96(3), 199-208

Karimbux NY, Nishimura I (1995): Temporal and spatial expressions of type XII collagen in the remodeling periodontal ligament during experimental tooth movement. J Dent Res $\underline{74}(1)$, $313-8$

Karimbux NY, Rosenblum ND, Nishimura I (1992): Site-specific expression of collagen I and XII mRNAs in the rat periodontal ligament at two developmental stages. J Dent Res $\underline{71(7),}$ $1355-62$

Karring T, Löe H (1970): The three-dimensional concept of the epithelium-connective tissue boundary of gingiva. Acta Odontol Scand 28(6), 917-33

Kemp KC, Hows J, Donaldson C (2005): Bone marrow-derived mesenchymal stem cells. Leuk Lymphoma $\underline{46}(11), 1531-44$

Kennedy JE, Polson AM (1973): Experimental marginal periodontitis in squirrel monkeys. J Periodontol $\underline{44}(3), 140-4$ 
Kim SS, Kwon DW, Im I, Kim YD, Hwang DS, Holliday LS, Donatelli RE, Son WS, Jun ES (2012): Differentiation and characteristics of undifferentiated mesenchymal stem cells originating from adult premolar periodontal ligaments. Korean J Orthod 42(6), 307-17

Klingsberg J, Butcher EO (1960): Comparative histology of age changes in oral tissues of rat, hamster, and monkey. J Dent Res $\underline{39}$, 158-69

Kolenbrander PE, London J (1993): Adhere today, here tomorrow: oral bacterial adherence. J Bacteriol 175(11), 3247-52

Lekic PC, Pender N, McCulloch CA (1997): Is fibroblast heterogeneity relevant to the health, diseases, and treatments of periodontal tissues? Crit Rev Oral Biol Med $\underline{8}$ (3), 253-68

Leonardi R, Loreto C, Caltabiano R, Caltabiano C (2006): Immunolocalization of CD44s in human teeth. Acta Histochem 108(6), 425-9

Listgarten MA (1980): Periodontal probing: what does it mean? J Clin Periodontol $\underline{7}(3), 165-$ 76

Listgarten MA (1986): Pathogenesis of periodontitis J Clin Periodontol 13(5), 418-30

Liu HW, Yacobi R, Savion N, Narayanan AS, Pitaru S (1997): A collagenous cementumderived attachment protein is a marker for progenitors of the mineralized tissue-forming cell lineage of the periodontal ligament. J Bone Miner Res $\underline{12}(10), 1691-9$

Löe H, Anerud A, Boysen H, Morrison E (1986): Natural history of periodontal disease in man. Rapid, moderate and no loss of attachment in Sri Lankan laborers 14 to 46 years of age. J Clin Periodontol $\underline{13}(5), 431-45$

Lukinmaa PL, Waltimo J (1992): Immunohistochemical localization of types I, V, and VI collagen in human permanent teeth and periodontal ligament. J Dent Res $\underline{71(2), 391-7}$

Lukinmaa PL, Mackie EJ, Thesleff I (1991): Immunohistochemical localization of the matrix glycoproteins- tenascin and the ED-sequence-containing form of cellular fibronectin- in human permanent teeth and periodontal ligament. J Dent Res $\underline{70}(1), 19-26$

Lunstrum GP, McDonough AM, Marinkovich MP, Keene DR, Morris NP, Burgeson RE (1992): Identification and partial purification of a large, variant form of type XII collagen. J Biol Chem 267(28), 20087-92 
Määttä M, Virtanen I, Burgeson R, Autio-Harmainen H (2001): Comparative analysis of the distribution of laminin chains in the basement membranes in some malignant epithelial tumors: the alphal chain of laminin shows a selected expression pattern in human carcinomas. J Histochem Cytochem 49 (6), 711-26

MacNeil RL, Berry JE, Strayhorn CL, Shigeyama Y, Somerman MJ (1998): Expression of type I and XII collagen during development of the periodontal ligament in the mouse. Arch Oral Biol $\underline{43}(10), 779-87$

Matias MA, Li H, Young WG, Bartold PM (2003): Immunohistochemical localisation of extracellular matrix proteins in the periodontium during cementogenesis in the rat molar. Arch Oral Biol $\underline{48}(10), 709-16$

Matsuo M, Takahashi K (2002): Scanning electron microscopic observation of microvasculature in periodontium. Microsc Res Tech $\underline{56}(1), 3-14$

McCulloch CA, Nemeth E, Lowenberg B, Melcher AH (1987): Paravascular cells in endosteal spaces of alveolar bone contribute to periodontal ligament cell populations. Anat Rec $\underline{219}(3), 233-42$

McKenzie JL, Fabre JW (1981 a): Human thy-1: unusual localization and possible functional significance in lymphoid tissues. J Immunol 126(3), 843-50

McKenzie JL, Fabre JW (1981 b): Distribution of Thy-1 in human brain: immunofluorescence and absorption analyses with a monoclonal antibody. Brain Res $\underline{230}(1-2), 307-16$

Moore WEC, Moore VH (1994): The bacteria of periodontal diseases. Periodontol $2000 \underline{5}$, $66-77$

Murakami S, Saho T, Asari A, Hino E, Kasai D, Shimabukuro Y, Okada H (1996): CD44hyaluronate interaction participates in the adherence of T-lymphocytes to gingival fibroblasts. $\mathrm{J}$ Dent Res $\underline{75}(8), 1545-52$

Nagata K, Huang YH, Ohsaki Y, Kukita T, Nakata M, Kurisu K (1992): Demonstration of type III collagen in the dentin of mice. Matrix 12(6), 448-55

Nagatomo K, Komaki M, Sekiya I, Sakaguchi Y, Noguchi K, Oda S, Muneta T, Ishikawa I (2006): Stem cell properties of human periodontal ligament cells. J Periodontal Res 41 (4), 303 10

Nanci A, Bosshardt DD (2006): Structure of periodontal tissues in health and disease. Periodontol $2000 \underline{40}, 11-28$ 
Narajanan AS, Page RC (1976): Biochemical characterization of collagens synthesized by fibroblasts derived from normal and diseased human gingiva. J Biol Chem 251(18), 5464-71

Nowack H, Gay S, Wick G, Becker U, Timpl R (1976): Preparation and use in immunohistology of antibodies specific for type I and type III collagen and procollagen. J Immunol Methods. 12(1-2), 117-24

Oh JY, Roddy GW, Choi H, Lee RH, Ylöstalo JH, Rosa RH Jr, Prockop DJ (2010): Antiinflammatory protein TSG-6 reduces inflammatory damage to the cornea following chemical and mechanical injury. Proc Natl Acad Sci U S A 107(39), 16875-80

Oh SP, Griffith CM, Hay ED, Olsen BR (1993): Tissue-specific expression of type XII collagen during mouse embryonic development. Dev Dyn 196(1), 37-46

Oksala O, Haapasalmi K, Häkkinen L, Uitto VJ, Larjava H (1997): Expression of heparan sulphate and small dermatan/chondroitin sulphate proteoglycans in chronically inflamed human periodontium. J Dent Res $\underline{76}(6), 1250-9$

Orban B (1948): Clinical and histologic study of the surface characteristics of the gingiva. Oral Surg $\underline{1}(9), 827-41$

Page RC, Kornman KS (1997): The pathogenesis of human periodontitis: an introduction. Periodontol $2000 \underline{14}, 9-11$

Page RC, Offenbacher S, Schroeder HE, Seymour GJ, Kornman KS (1997): Advances in the pathogenesis of periodontitis: summary of developments, clinical implications and future directions. Periodontol $2000 \underline{14}, 216-248$

Park JC, Kim JM, Jung IH, Kim JC, Choi SH, Cho KS, Kim CS (2011): Isolation and characterization of human periodontal ligament (PDL) stem cells (PDLSCs) from the inflamed PDL tissue: in vitro and in vivo evaluations. J Clin Periodontol $\underline{38}(8), 721-31$

Preshaw PM, Seymour RA, Heasman PA (2004): Current concepts in periodontal pathogenesis. Dent Update $\underline{31}(10), 570-2,574-8$

Raspanti M, Cesari C, De Pasquale V, Ottani V, Strocchi R, Zucchelli G, Ruggeri A (2000): A histological and electron-microscopic study of the architecture and ultrastructure of human periodontal tissues. Arch Oral Biol 45(3), 185-92

Rege TA, Hagood JS (2006): Thy-1 as a regulator of cell-cell and cell-matrix interactions in axon regeneration, apoptosis, adhesion, migration, cancer, and fibrosis. FASEB J 20 (8), $1045-$ 54 
Reid G (1999): Biofilms in infectious disease and on medical devices. Int J Antimicrob Agents $\underline{11}(3-4), 223-6,237-9$

Roberts WE, Chamberlain JG (1978): Scanning electron microscopy of the cellular elements of rat periodontal ligament. Arch Oral Biol 23(7), 587-9

Roberts WE, Chase DC (1981): Kinetics of cell proliferation and migration associated with orthodontically-induced osteogenesis. J Dent Res $\underline{60}(2), 174-81$

Romanos GE, Schröter-Kermani C, Hinz N, Wachtel HC, Bernimoulin JP (1992): Immunohistochemical localization of collagenous components in healthy periodontal tissues of the rat and marmoset (Callithrix jacchus). I. Distribution of collagen types I and III. J Periodontal Res $\underline{27}(2), 101-10$

Saalbach A, Aneregg U, Bruns M, Schnabel E, Herrmann K, Haustein UF (1996): Novel fibroblast-specific monoclonal antibodies: properties and specificities. J Invest Dermatol $\underline{106}(6), 1314-9$

Saalbach A, Kraft R, Herrmann K, Haustein UF, Anderegg U (1998): The monoclonal antibody AS02 recognizes a protein on human fibroblasts being highly homologous to Thy-1. Arch Dermatol Res 290(7), 360-6

Saalbach A, Wetzig T, Haustein UF, Anderegg U (1999): Detection of human soluble Thy-1 in serum by ELISA. Fibroblasts and activated endothelial cells are a possible source of soluble Thy-1 in serum. Cell Tissue Res 298(2), 307-15

Saalbach A, Haustein UF, Anderegg U (2000): A ligand of human thy-1 is localized on polymorphonuclear leukocytes and monocytes and mediates the binding to activated thy-1positive microvascular endothelial cells and fibroblasts. J Invest Dermatol 115(5), 882-8

Saffar JL, Lasfargues JJ, Cherruau M (1997): Alveolar bone and the alveolar process: the socket that is never stable. Periodontol $2000 \underline{13}, 76-90$

Salvi GE, Lawrence HP, Offenbacher S, Beck JD (1997): Influence of risk factors on the pathogenesis of periodontitis. Periodontol $2000 \underline{14}, 173-201$.

Scannapieco FA, Bush RB, Paju S (2003): Associations between periodontal disease and risk for atherosclerosis, cardiovascular disease, and stroke. A systematic review. Ann Periodontol $\underline{8}(1), 38-53$

Schroeder HE (1973): Transmigration and infiltration of leucocytes in human junctional epithelium. Helv Odontol Acta 17(1), 6-18 
Schroeder HE: The Periodontium; in: Handbook of microscopic anatomy, volume 5; Springer-Verlag, Berlin Heidelberg 1986, 129-164

Schroeder HE: Orale Strukturbiologie, 5. Auflage; Thieme Verlag, Stuttgart 2000

Schroeder HE, Theilade J (1966): Electron microscopy of normal human gingival epithelium. J Periodontal Res $\underline{1}(2), 95-119$

Schroeder HE, Listgarten MA (1971): Fine structure of the developing epithelial attachment of human teeth. Monogr Dev Biol 2, 1-134

Schroeder HE, Lindhe J (1975): Conversion of stable established gingivitis in the dog into destructive periodontitis. Arch Oral Biol 20(12), 775-82

Schroeder HE, Listgarten MA (1997): The gingival tissues: the architecture of periodontal protection. Periodontol $2000 \underline{13}, 91-120$

Selvig KA (1965): The fine structure of human cementum. Acta Odontol Scand 23(4), 423-41

Shore RC, Berkovitz BK (1979): An ultrastructural study of periodontal ligament fibroblasts in relation to their possible role in tooth eruption and intracellular collagen degradation in the rat. Arch Oral Biol 24(2), 155-64

Sims MR (1975): Oxytalan-vascular relationships observed in histologic examination of the periodontal ligaments of man and mouse. Arch Oral Biol. 20(11), 713-6

Skougaard MR (1965): Turnover of the gingival epithelium in marmosets. Acta Odontol Scand $\underline{23}(6), 623-43$

Skougaard MR (1970): Cell renewal, with special reference to the gingival epithelium. Adv Oral Biol $\underline{4}, 261-88$

Socransky SS, Haffajee AD, Cugini MA, Smith C, Kent RL Jr. (1998): Microbial complexes in subgingival plaque. J Clin Periodontol 25(2), 134-44

Sodek J, McKee MD (2000): Molecular and cellular biology of alveolar bone. Periodontol $2000 \underline{24}, 99-126$

Stefanovic B, Schnabl B, Brenner DA (2002): Inhibition of collagen alpha 1(I) expression by the 5' stem-loop as a molecular decoy. J Biol Chem 277(20), 18229-37

Steffensen B, Duong AH, Milam SB, Potempa CL, Winborn WB, Magnuson VL, Chen D, Zardeneta G, Klebe RJ (1992): Immunohistological localization of cell adhesion proteins and integrins in the periodontium. J Periodontol 63(7), 584-92 
Stein MF: Individualisierte Microarrayanalyse von PDL-Gewebe von Patienten mit Parodontitis. Med. Diss. Göttingen 2011

Szydlik S: Vergleichende Genexpressionsanalysen von Komponenten der extrazellulären Matrix im parodontal gesunden Gewebe und bei der chronischen Parodontitis in vivo. Med. Diss. Göttingen 2009

Takita K, Ohsaki Y, Nakata M, Kurisu K (1987): Immunofluorescence localization of type I and type III collagen and fibronectin in mouse dental tissues in late development and during molar eruption. Arch Oral Biol 32(4), 273-9

Taylor GW (2001): Bidirectional interrelationships between diabetes and periodontal diseases: an epidemiologic perspective. Ann Periodontol $\underline{6}(1), 99-112$

Ten Cate AR, Mills C (1972): The development of the periodontium: the origin of alveolar bone. Anat Rec 173(1), 69-77

Ten Cate AR, Mills C, Solomon G (1971): The development of the periodontium. A transplantation and autoradiographic study. Anat Rec 170(3), 365-79

Tomokiyo A, Maeda H, Fujii S, Monnouchi S, Wada N, Kono K, Yamamoto N, Koori K, Teramatsu Y, Akamine A (2012): A multipotent clonal human periodontal ligament cell line with neural crest cell phenotypes promotes neurocytic differentiation, migration, and survival. J Cell Physiol 227(5), 2040-50

Topoll HH, Zwadlo G, Lange DE, Sorg C (1989): Phenotypic dynamics of macrophage subpopulations during human experimental gingivitis. J Periodontal Res $\underline{24}(2), 106-12$

Toto PD, Rubinstein AS, Gargiulo AW (1975): Labeling index and cell density of aging rat oral tissues. J Dent Res $\underline{54}(3), 553-6$

Trubiani O, Di Primio R, Traini T, Pizzicannella J, Scarano A, Piattelli A, Caputi S (2005): Morphological and cytofluorimetric analysis of adult mesenchymal stem cells expanded ex vivo from periodontal ligament. Int J Immunopathol Pharmacol 18(2), 213-21

Wada N, Menicanin D, Shi S, Bartold PM, Gronthos S (2009): Immunomodulatory properties of human periodontal ligament stem cells. J Cell Physiol 219(3), 667-76

Wälchli C, Koch M, Chiquet M, Odermatt BF, Trueb B (1994): Tissue-specific expression of the fibril-associated collagens XII and XIV. J Cell Sci 107(Pt 2), 669-81 
Wang HM, Nanda V, Rao LG, Melcher AH, Heersche JN, Sodek J (1980): Specific immunohistochemical localization of type III collagen in porcine periodontal tissues using the peroxidase-antiperoxidase method. J Histochem Cytochem 28(11), 1215-23

Wayner EA, Carter WG (1987): Identification of multiple cell adhesion receptors for collagen and fibronectin in human fibrosarcoma cells possessing unique alpha and common beta subunits. J Cell Biol 105(4), 1873-84

Wesselink PR, Beertsen W (1993): The prevalence and distribution of rests of Malassez in the mouse molar and their possible role in repair and maintenance of the periodontal ligament. Arch Oral Biol 38 (5), 399-403

Whittaker CJ, Klier CM, Kolenbrander PE (1996): Mechanisms of adhesion by oral bacteria. Annu Rev Microbiol 50, 513-52

Yura T, Osatake H, Inoué T (2000): Three-dimensional structure of connective tissue papillae in the human gingiva. Yonago Acta medica $\underline{43}, 39-46$

Zhang G, Young BB, Birk DE (2003): Differential expression of type XII collagen in developing chicken metatarsal tendons. J Anat 202(5), 411-20

Zhang X, Schuppan D, Becker J, Reichart P, Gelderblom HR (1993): Distribution of undulin, tenascin, and fibronectin in the human periodontal ligament and cementum: comparative immunoelectron microscopy with ultra-thin cryosections. J Histochem Cytochem $\underline{41}(2), 245-51$

Zwarych PD, Quigley MB (1965): The intermediate plexus of the periodontal ligament: history and further observations. J Dent Res $\underline{44}, 383-91$ 


\section{Danksagung}

Mein besonderer Dank gilt Herrn Prof. Dr. med. Nicolai Miosge für die stets gute wissenschaftliche Betreuung während meiner Zeit als Doktorand.

Der Abteilung Mund-, Kiefer- und Gesichtschirurgie und hierbei insbesondere Herrn ZA Jan Alexander Klenke danke ich für die Unterstützung bei der Gewinnung der Gewebeproben.

Ferner möchte ich mich bei allen Mitarbeitern der Arbeitsgemeinschaft „Orale Biologie und Geweberegeneration“ bedanken, insbesondere bei Boguscha Sadowski, Christa Bode, Moritz Roth, Matz Menrath, Gökhan Cingöz, Boris Schminke und Hajat Muhammad, die mir stets hilfsbereit zur Seite standen. 